\title{
A Process for an Efficient Heat Release Prediction at Multiple Engine Speeds and Valve Timings in the Early Stage of Gasoline Engine Development
}

\author{
Author, co-author (Do NOT enter this information. It will be pulled from participant tab in \\ MyTechZone) \\ Affiliation (Do NOT enter this information. It will be pulled from participant tab in MyTechZone)
}

\begin{abstract}
The increasing need for cleaner and more efficient combustion systems has promoted a paradigm shift in the automotive industry. Virtual hardware and engine calibration screening at the early development stage, has become the most effective way to reduce the time necessary to bring new products to market. Virtual engine development processes need to provide realistic engine combustion rate responses for the entire engine map and for different engine calibrations. Quasi Dimensional (Q-D) combustion models have increasingly been used to predict engine performance at multiple operating conditions. The physics-based Q-D turbulence models necessary to correctly model the engine combustion rate within the Q-D combustion model framework are a computationally efficient means of capturing the effect of port and combustion chamber geometry on performance. A rigorous method of correlating the effect of air motion on combustion parameters such as heat release is required to enable novel geometric architectures to be assessed to deliver future improvements in engine performance.
\end{abstract}

A previously assessed process using a combination of a 0-D combustion Stochastic Reactor Model (SRM), provided by LOGESoft, a 1-D engine system model and non-combusting, 'cold' CFD is used. The approach uses a single baseline CFD run and a user developed scalar mixing time ( $\tau_{\mathrm{SRM}}$ ) response to quickly predict the Rate of Heat Release (RoHR). In this work, the physically-based response for $\tau$ SRM has been further developed to consider the effect of Variable Valve Timing (VVT) for a variety of engine operating conditions. Cold CFD and 1-D engine simulations have initially been carried out to investigate changes in Turbulent Kinetic Energy (k) and its dissipation ( $\varepsilon$ ) caused by VVT changes, allowing the engine Rate of Heat Release (RoHR) to be predicted. The change in the intake flow velocity was correlated to the scalar mixing time, $\tau_{S R M}$ resulting in a good engine RoHR prediction at the explored conditions.

\section{Introduction}

Virtual engineering tools have become an efficient solution for developing cleaner and more fuel-efficient engines, shortening the required time to bring products to market $[1,2]$. Different combustion system configurations and attributes are virtually tested in the early stages of engine development to define the final powertrain design. Thus, the engine Rate of Heat Release (RoHR) of different high-level engine calibrations and hardware configurations need to be known in advance of the hardware being available. In the author's previous work [3], it was shown that a virtual development process, allowing the engine RoHR prediction at different engine calibrations and during the

Page 1 of 20 hardware screening phase, is needed to ensure that customers and market requirements are successfully met.

Virtual engine development processes based on Direct Numerical Simulation (DNS) CFD calculations can offer predictive results without any tuning but associated run times and costs are unsuitable for engine development [4]. Shorter running times can be achieved using the 3-D CFD RANS approach but at the cost of accuracy [4]. However, calculation times are still unacceptable for virtual concept screening. Moreover, during the early stages of engine development the detailed geometry is not available limiting the value of high accuracy multi-dimensional modelling approaches. A practical and frequently adopted solution, to carry out a combustion analysis while meeting restrictive development times, is to use 0-D/Q-D combustion sub-models within the 1-D modelling framework. Figure 1 shows an example of an ideal engine development process for SI engines. The methodology is based on three different simulation levels. 3-D noncombusting CFD, for each explored hardware to characterize its effect on the in-cylinder turbulence. A 1-D engine system model accounting for air handling. Finally, a Q-D Stochastic Reactor Model (SRM) run "in the loop" to deliver the key engine performance parameters and the engine burn rate. The SRM combustion model, uses a Probability Density Function (PDF) applied to turbulent flows to account for turbulence-chemistry interaction allowing the combustion rates to be analyzed [3, 5-8]. Figure 1 uses a turbulence response, to derive the incylinder turbulence response to different high-level engine calibrations, providing the needed turbulent input for the SRM to correctly predict the engine RoHR. A turbulence response was initially developed in [3] and applied to a process similar to Figure 1, however, the 1-D engine system model was only used to provide the SRM model with the correct boundary condition instead of running simultaneously with the Q-D model. Initial results suggested that a virtual approach based on an SRM combustion model and a 1-D engine system running in co-simulation, such as the one presented in Figure 1, could be achieved. Other simplified Q-D / 0-D combustion models, have been demonstrated to accurately predict the engine RoHR [9-14]. Among the Spark Ignited (SI) engine combustion modelling framework, it is well understood that the in-cylinder turbulence is one of the main inputs required by all Q-D / 0-D combustion models to correctly predict the RoHR. The turbulence response referred to in Figure 1, can therefore be considered as a tabulated turbulence model. Different turbulent flame propagation models, such as the entrained model [9, $15]$ and the fractal model $[9,16]$, have been developed to account for the effect of the turbulent SI engine in-cylinder flows on the laminar flame speed [17, 18]. Nonetheless, these models' combustion results still rely on the initial turbulence input derived either experimentally or numerically from a turbulence model. Reliable 0-D in-cylinder turbulence models capable of predicting the in-cylinder turbulence 
generation at different engine operating points and engine calibration are therefore necessary to allow Q-D / 0-D combustion models to predict the engine RoHR within the 1-D engine simulation framework. Moreover, burn angle and knock limit prediction within $\pm 2{ }^{\circ} \mathrm{CA}$ from experimental (averaged) data is required to consider a methodology a practical solution during the initial hardware screening phase of engine development.

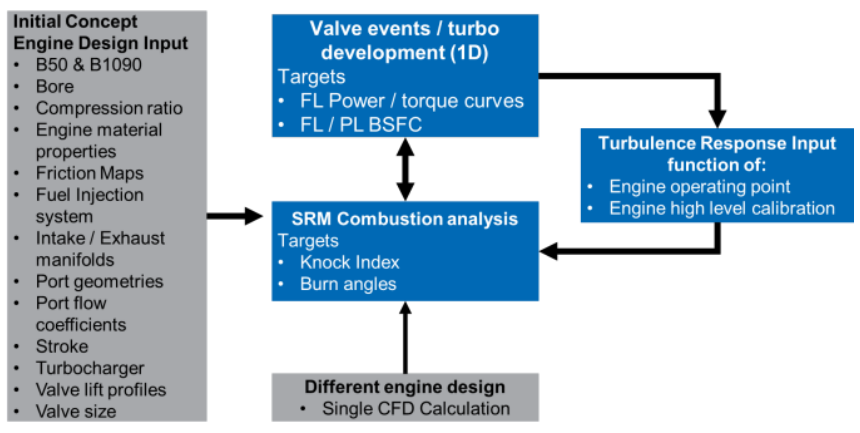

Figure 1: Schematic of an ideal virtual engine development process.

In the SI engine combustion regime, the large scale tumble motion generated during the intake stroke collapses into smaller scales during compression prior firing TDC and it is known to significantly influence the combustion process in SI engines $[1,2]$. The tumble generation occurs mainly thanks to the intake port geometry. Nevertheless, other engine characteristics such as, valve strategy, bore-to-stroke $(\mathrm{B} / \mathrm{S})$ ratio, compression ratio (CR) and fuel injection can influence the tumble structure during the combustion stroke [1, 2, 19-21]. Low B/S ratio (below unity) reduces the maximum flame path length, reducing the time available for auto-ignition reactions to occur [1]. High CRs are instead adopted to increase the engine thermal efficiency. Valve timing is known to have a significant effect on the in-cylinder turbulence generation and thus, on the engine tumble ratio. Improved engine fuel consumption can be achieved with optimized valve timings thanks to a reduction in the engine pumping losses. Engine knock tolerance can also improve thanks to lower in-cylinder charge temperatures $[1,2]$. However, either extreme late or extreme early IVC timings can negatively affect the turbulence formation towards TDC resulting in slower engine combustion rates [22]. Regardless of the adopted solution, increased tumble ratios are generally related to improved SI engine performance and fuel consumption [19, 23].

0-D turbulence models, to be considered predictive, need to capture the effect of different combustion system configurations and engine operating points. Different 0-D turbulence modelling approaches have therefore been developed. Some of the 0 -D turbulence models simplify 3 -D CFD equations for the turbulent kinetic energy, $k$, and dissipation rate, $\varepsilon$ and are known as $k-\varepsilon$ models [11, 12, 24-26]. Another modelling approach, to better account for the effect of the ordered large tumble structure on the in-cylinder turbulence, calculates the turbulent kinetic energy, $k$, through an energy cascade from the mean flow kinetic energy, K. Turbulence models based on this approach are generally known as K- $k$ models. The turbulent dissipation rate is calculated using the integral length scale, $l_{l}$, known to be only slightly dependent on the engine operating condition, and therefore only depending on the piston position [27]. Improvements to the original K- $k$ turbulence approach have been developed to better describe the structured tumble motion throughout the engine cycle in [28, 29]. Tumble level and its decay during the compression stroke due to shear stresses have been related to the piston position. A third modelling approach called $\mathrm{K}-k-\varepsilon$ turbulence model, merged the previous two approaches together [30]. Irrespective of the approach used, all these models require an extensive 2 of 20 validation to experimental data. The engine air motion data, necessary to validate any turbulence model, could either be derived from optical access engines, or numerical combustion rates, calculated by coupled 0 -D combustion models, may be used to indirectly compare 0-D turbulence results. Thanks to improved 3-D CFD simulation accuracy and growing computational power, some studies have conducted turbulence model validation based on 3-D CFD results. [27-29]. Regarding the SRM, different studies have shown how the SRM coupled with a 0-D turbulence model can be used to predict the engine combustion rate for an entire engine map [31-33]. The methodology was successfully used to predict the RoHR and carry a virtual engine calibration out thanks to an initial model training against multiple engine operating points.

Due to the complex three-dimensional nature of in-cylinder flow, most of the available 0-D turbulence models still fail in correctly predicting the turbulence for multiple operating points and different combustion system concepts. Due to a lack of extensive model validation, different tuning constants are therefore generally available within 0-D turbulence models and need to be adjusted to account for changes in geometry or investigation of new technologies making these approaches not suitable in the early development stage. An example of an alternative solution that avoids the need of time-consuming validation for the $0-\mathrm{D}$ turbulence model was presented by Pasternak $[34,35]$. 3-D non-combusting CFD simulations have been carried out to analyze the in-cylinder turbulence and subsequently used as input for an SRM 0-D combustion model, without requiring any extra turbulence sub-model. Pasternak's simulation work flow showed how a multi-dimensional virtual engine development approach not relying on previous test data, comparable to Figure 1, could be successfully achieved. Nevertheless, deriving the necessary turbulence input from 3-D CFD runs for different engine characteristics and high-level calibration make Pasternak's solution effectively impractical for virtual engine development.

In our previous work, the turbulence response to engine load and injection timings, to allow the engine RoHR to be correctly predicted, was presented [3]. In this work, the response was further developed to account for different engine speeds, valve timings and charge dilution. In-cylinder air motion changes to engine operating conditions were related to predicted 1-D gas dynamic physical responses. Multiple 3D non-combusting CFD calculations were carried out to characterize and capture the turbulence changes to different valve timings and engine speed. Afterwards, the response in the intake port velocity, predicted by the 1-D engine system model, was correlated to the SRM turbulence input known as turbulent scalar mixing, $\tau_{S R M}$. The incylinder air motion response to different high-level engine calibrations, such as valve timings, was correctly derived. The engine burning rate was then predicted by the SRM combustion model resulting in good agreement with experimental combustion data at the explored conditions, without the need for an additional turbulence submodel. A single non-combusting 3-D CFD calculation was used to calibrate the SRM combustion model. The in-cylinder turbulence evolution from different high-level engine calibrations was derived by the developed correlation, allowing the engine RoHR prediction during the initial phase of engine development. This suggests that a single non-combusting CFD calculations could be used to characterize the effect of any explored engine design on the in-cylinder air motion. The presented methodology offers a practical solution to provide 0-D combustion models with the correct turbulence information without the need of any extra turbulence sub-models. Future work is still required to assess the correlation to a wider combustion range of engine operating condition. Alternative fuels and new combustion designs need to be tested to verify the process's predictive capabilities for future powertrain. 


\section{Methodology}

This study is carried out using the LOGESoft SRM combustion model with 1-D engine simulation and 3-D cold CFD calculations. For this work the SRM and 1-D simulation were run independently. SRM boundary conditions at IVC were extracted from the 1-D engine system model and applied as boundary conditions in the SRM. Ideally, the SRM and 1-D simulations would run simultaneously as presented in Figure 1. This is for future work.

\section{Experimental Data}

Experimental data from a three-cylinder gasoline engine was used. The engine was a Euro 6 stoichiometric port-injected engine with the geometry shown in Table 1. Table 3 shows the experimental conditions studied. Four different engine speed points have been selected for this study. VVT swings have been carried out at all operating points, maintaining CA50 angle constant at around $8{ }^{\circ} \mathrm{CA}$ ATDC $(\mathrm{F})$ or at the equivalent angle for Minimum advance for Best Torque (MBT). The maximum external EGR rate achievable combined with ignition timing advance have been set to maintain CA50 at the desired value. Furthermore, EGR swings have been carried out using constant valve timings. Table 3 summarizes the explored engine operating points. The valve lift profiles used for the study are shown in Figure 2. 300 consecutive engine cycles have been recorded for each of the operating points in Table 3 . Average pressure traces have been arithmetically calculated. The standard deviations of the experimental burn angles have been derived from the high-speed data logger over 300 engine cycles following Equation 1.

Standard Deviation $(i)=\sqrt{\frac{\left(n \sum_{j=i-n+1}^{i} C A_{j}^{2}-\left(\sum_{j=i-n+1}^{i} C A_{j}\right)^{2}\right)}{n *(n-1)}}$

- $\mathrm{n}=$ engine cycles

Equation 1: Experimental Burn Angle Standard Deviation

\begin{tabular}{|l|l|}
\hline Displaced volume & $650 \mathrm{cc}$ \\
\hline Bore-to-stroke ratio & 0.83 \\
\hline Compression ratio & 12.1 \\
\hline Number of valves & 4 \\
\hline Number of cylinders & 3 \\
\hline Fuel injection system & Port injection \\
\hline Induction & Naturally aspirated \\
\hline
\end{tabular}

Table 1: Main Engine Parameters

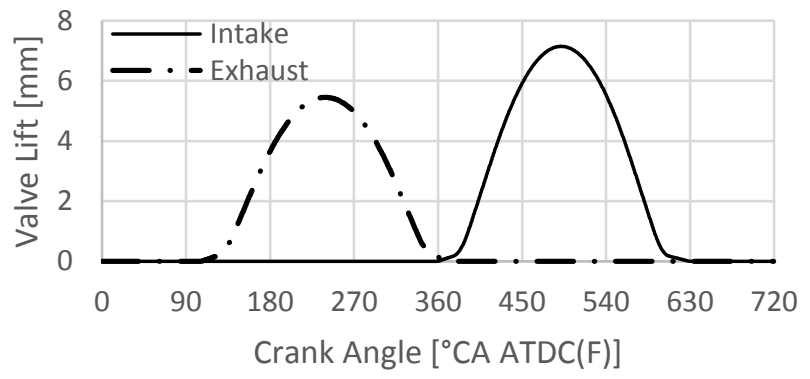

Figure 2: Valve Lift

\section{3 -D Non-Combusting In-Cylinder Simulation}

The Ricardo Software CFD package VECTIS [36] was used to carry out the in-cylinder turbulence analysis. Non-combusting CFD calculations provide the SRM with a turbulence input. Similar 3-D CFD codes would therefore be suitable for the proposed methodology.

Three consecutive engine cycles were simulated to reach model convergence. Results presented in this paper have been extracted from the third engine cycle. A global mesh size of $2 \mathrm{~mm}$ was used following VECTIS guidelines for in-cylinder simulations [36]. The in-cylinder air motion was modelled using the standard $k-\varepsilon$ RANS turbulence model. Default values were used for all the user defined model constants except for the turbulence limiter (TSB). The TSB limiter is a tunable parameter implemented in VECTIS to influence the effect of the turbulent viscosity $\mu_{t}$ on the simulation results [36]. A more detailed explanation of the TSB can be found in [3, 36, 37]. Figure 3 shows the engine geometry and the chosen CFD mesh. Main 3-D CFD parameters are summarized in Table 2. Port boundary conditions are extracted from the 1-D WAVE model and imposed to the VECTIS. Constant wall temperatures have been derived from the 1-D calculations as described in [36].

\begin{tabular}{|l|l|}
\hline Turbulence Model & RANS K-Epsilon \\
\hline Wall Function & Non-Isothermal \\
\hline Turbulence Limiter & 0.346 \\
\hline
\end{tabular}

Table 2: 3-D CFD main parameters

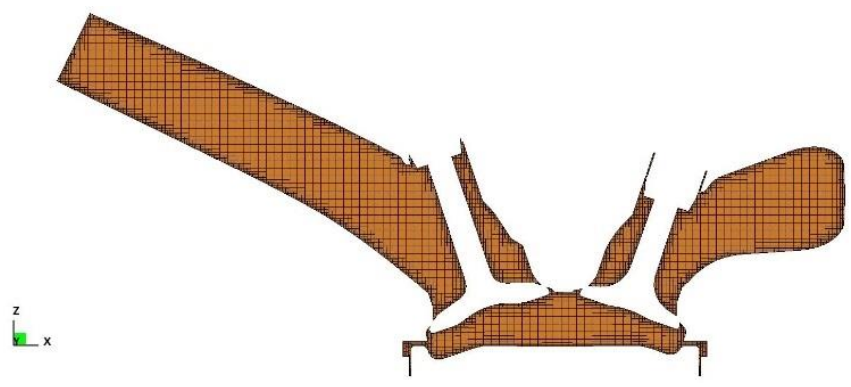

Figure 3: Valves section 3D CFD mesh

\section{1-D Engine Simulation}

The WAVE [38] package developed by Ricardo Software was used to evaluate the overall engine performance at the experimental operating points described in Table 3. The WAVE model was tuned and validated against experimental data to extract the necessary boundary conditions for the SRM as explained previously [3]. Future work is still required to develop an automatic procedure that would allow to couple the 1-D model to the SRM and feedback the combustion results. Any other 1-D engine simulation tool, capable of providing the SRM with the correct boundary conditions, would be suitable for the proposed methodology.

\section{SI Stochastic Reactor Model}

The 0-D SRM combustion tool developed by LOGESoft was used for this study. The SRM uses the PDF approach applied to turbulent flows to model the main physical processes occurring during engine combustion, piston motion, flame propagation, mixing, chemical reactions and heat transfer [39-41]. The detailed chemical kinetics library available within the SRM allow evaluation of the engine knock tolerance [8, 34, 35, 42]. A more detailed explanation of the SRM can be found in our previous work [3]. Most of the SRM input variables 
were kept as prescribed in [41] and further explained in [3]. Geometrical dependent input variables were set according to the engine size and the integral length scale $l$, which is necessary to calculate the turbulent flame speed, was set to half of the cylinder bore. The mixing model integral to the PDF approach is based on the work presented by Curl $[43,44]$. Default constants prescribed in the software manual [41] were used in the present work. The SRM simulations were carried out over the closed part of the cycle and all the necessary boundary conditions were extracted from the WAVE model as explained in [3].

\section{3-D Non-combusting In-Cylinder Turbulence Analysis Results}

The bulk in-cylinder motion changes in response to the operating condition. The proposed analytical process needs therefore to correctly derive the turbulence response to predict the engine RoHR. In this work, Key Point 1 in Table 3 was used as baseline case to calibrate the SRM and assess the process predictive capabilities. A 3-D noncombusting analysis was carried out to assess the effect of different valve timings and engine speeds on main in-cylinder turbulence characteristics. Afterwards, the turbulence response for the SRM in Figure 1 was further developed to account for the valve timing and the engine speed.

\begin{tabular}{|c|c|c|c|c|c|c|c|}
\hline $\begin{array}{l}\text { Key } \\
\text { Point }\end{array}$ & $\begin{array}{c}\text { Speed } \\
{[\mathrm{rev} / \mathrm{min}]}\end{array}$ & $\begin{array}{c}\text { BMEP } \\
\text { [bar] }\end{array}$ & $\begin{array}{c}\text { EGR } \\
\text { (Int.+Ext.) } \\
{[\%]} \\
\end{array}$ & $\begin{array}{c}\text { IVO } \\
{\left[{ }^{\circ} \mathrm{CA} \text { ATDC }(\mathrm{F})\right]}\end{array}$ & $\begin{array}{c}\text { IVC } \\
{\left[{ }^{\circ} \mathrm{CA} \text { ATDC }(\mathrm{F})\right]}\end{array}$ & $\begin{array}{c}\text { EVO } \\
{\left[{ }^{\circ} \mathrm{CA} \text { ATDC }(\mathrm{F})\right]}\end{array}$ & $\begin{array}{c}\text { EVC } \\
{\left[{ }^{\circ} \mathrm{CA} \operatorname{ATDC}(\mathrm{F})\right]}\end{array}$ \\
\hline 1 & 2000 & 7.5 & 21 & 334 & 604 & 121 & 390 \\
\hline 2 & 2000 & 7.5 & 18 & 344 & 614 & 111 & 400 \\
\hline 3 & 2000 & 7.5 & 16 & 354 & 624 & 141 & 410 \\
\hline 4 & 2000 & 7.5 & 29 & 334 & 604 & 121 & 390 \\
\hline 5 & 2000 & 7.5 & 17 & 334 & 604 & 121 & 390 \\
\hline 6 & 2000 & 7.5 & 14 & 334 & 604 & 121 & 390 \\
\hline 7 & 2000 & 7.5 & 12 & 334 & 604 & 121 & 390 \\
\hline 8 & 1300 & 6.5 & 26 & 329 & 599 & 136 & 405 \\
\hline 9 & 1300 & 6.5 & 26 & 349 & 619 & 116 & 375 \\
\hline 10 & 1300 & 6.5 & 24 & 339 & 609 & 146 & 415 \\
\hline 11 & 1300 & 6.5 & 26 & 349 & 619 & 146 & 415 \\
\hline 12 & 1300 & 6.5 & 23 & 349 & 619 & 146 & 415 \\
\hline 13 & 1300 & 6.5 & 20 & 349 & 619 & 146 & 415 \\
\hline 14 & 1300 & 6.5 & 17 & 349 & 619 & 146 & 415 \\
\hline 15 & 3500 & 8 & 8 & 359 & 629 & 136 & 405 \\
\hline 16 & 3500 & 8 & 17 & 349 & 619 & 146 & 415 \\
\hline 17 & 3500 & 8 & 18 & 349 & 619 & 126 & 395 \\
\hline 18 & 3500 & 8 & 18 & 349 & 619 & 126 & 395 \\
\hline 19 & 3500 & 8 & 14 & 349 & 619 & 126 & 395 \\
\hline 20 & 3500 & 8 & 10 & 349 & 619 & 126 & 395 \\
\hline 21 & 5500 & 11 & 3 & 354 & 624 & 116 & 385 \\
\hline 22 & 5500 & 11 & 3 & 344 & 614 & 116 & 385 \\
\hline 23 & 5500 & 11 & 3 & 344 & 614 & 136 & 405 \\
\hline 24 & 5500 & 11 & 3 & 334 & 604 & 126 & 395 \\
\hline
\end{tabular}

Table 3: Engine Operating Point 
Variable Valve Timing Effect on In-Cylinder

Turbulence

Figure 4 shows the 3-D CFD prediction results of the main in-cylinder mass-averaged turbulence characteristics for different valve timings at constant engine speed (Key Points 1,2 and 3 in Table 3). The mean flow velocity was calculated by averaging the three velocity components in the in-cylinder domain. The turbulence intensity, $u$, was calculated following Equation 2 and represents the flow characteristic velocity. The bulk in-cylinder angular velocity along the tumble axis was extracted and normalized to the engine speed to calculate the in-cylinder tumble ratio. Figure 4 a shows that the mean in-cylinder velocity is mainly generated during the initial part of the intake stroke with an initial decay corresponding to EVC timings. The most retarded IVO timing (Key point 3 ) results in the highest velocity formation due to a favorable intake valve pressure condition at IVC (see Figure 4a, b and Figure 5). Moreover, the in-cylinder velocity starts decreasing at around $450{ }^{\circ} \mathrm{CA}$ ATDC(F) for all the explored valve timings due to the piston moving towards BDC and the reduced intake flow rates.

Results show that the tumble profile follows the mean in-cylinder velocity and turbulence intensity's trends during the intake stroke (see Figure 4c). Afterwards, the profile is characterized by a significant increase due to IVC timings followed by a decay due to the piston moving toward BDC. The most retarded IVO timing (Key Point 3) showed the lowest tumble generation during the intake indicating an increased turbulent viscosity for corresponding late IVC timings. The tumble vortex increases during the compression stroke, after the piston reached BDC, until around $650{ }^{\circ} \mathrm{CA}$ ATDC $(\mathrm{F})$. Modern SI engines generate a bulk in-cylinder tumbling motion with a given vortex radius larger that the clearance volume. As the piston approaches TDC, the tumble vortex breaks up into several smaller eddies, thus resulting in a tumble decay. As the structured tumble motion starts collapsing due to increased dissipative effects, the in-cylinder mean flow velocity increases thanks to the flow angular momentum conservation. Results highlight that towards firing TDC, Key Point 3 shows the lowest tumble. This is likely to be due to higher pressure difference the intake valve at IVC resulting in greater intake back flows (see Figure 5), and in increased viscosity effects which further destroy the structured tumble motion. Figure $6 \mathrm{a}$, shows the in-cylinder turbulent dissipation rate, $\varepsilon$, during the compression and expansion strokes. Key Point 3 shows higher in-cylinder dissipation rate at IVC and close to TDC confirming that later IVC timings result in increased viscous stresses due to the back flow destroying the well-structured tumble vortex.

The effect of different valve timing, on the turbulent mixing time defined in Equation 3, during the compression and the expansion strokes is shown in Figure 6b. In-cylinder turbulence intensity, and therefore $k$ (see Equation 2), increases with the piston moving towards firing TDC. As the piston approaches firing TDC the viscous effects become more significant dissipating the flow energy into heat [4]. The initial drop seen in the turbulent mixing time profiles results at around $585{ }^{\circ} \mathrm{CA}$ ATDC(F) is due to the IVC timings and the significant $\varepsilon$ generation (see Figure 6a). Increased $k$ and $\varepsilon$ at EVO timings are instead the reason of the sudden drop in the turbulent mixing time profiles occurring during the late part of the expansion stroke. The most retarded IVC timing (Key point 3) results in greater turbulent mixing time profile, $\tau_{t}$ corresponding to lower level of in-cylinder turbulence during the combustion [3]. Since the turbulent flame speed within the SRM is proportional to $\tau_{t}$, greater turbulent mixing time corresponds to slower engine combustion rate [3]. $u$ ', and thus $k$, is not significantly affected by different valve timings during the closed part of the engine cycle (see Figure 4b). Moreover, at firing TDC, $u$ ' converges to a single value of about $1.4 \mathrm{~m} / \mathrm{s}$. The observed difference in $\tau_{t}$ is therefore due to the different viscous effect and thus, to the $\varepsilon$ generation occurring at IVC timings.

$$
u^{\prime}=\sqrt{\left(\frac{2}{3}\right) k}
$$

Equation 2 Turbulence Intensity
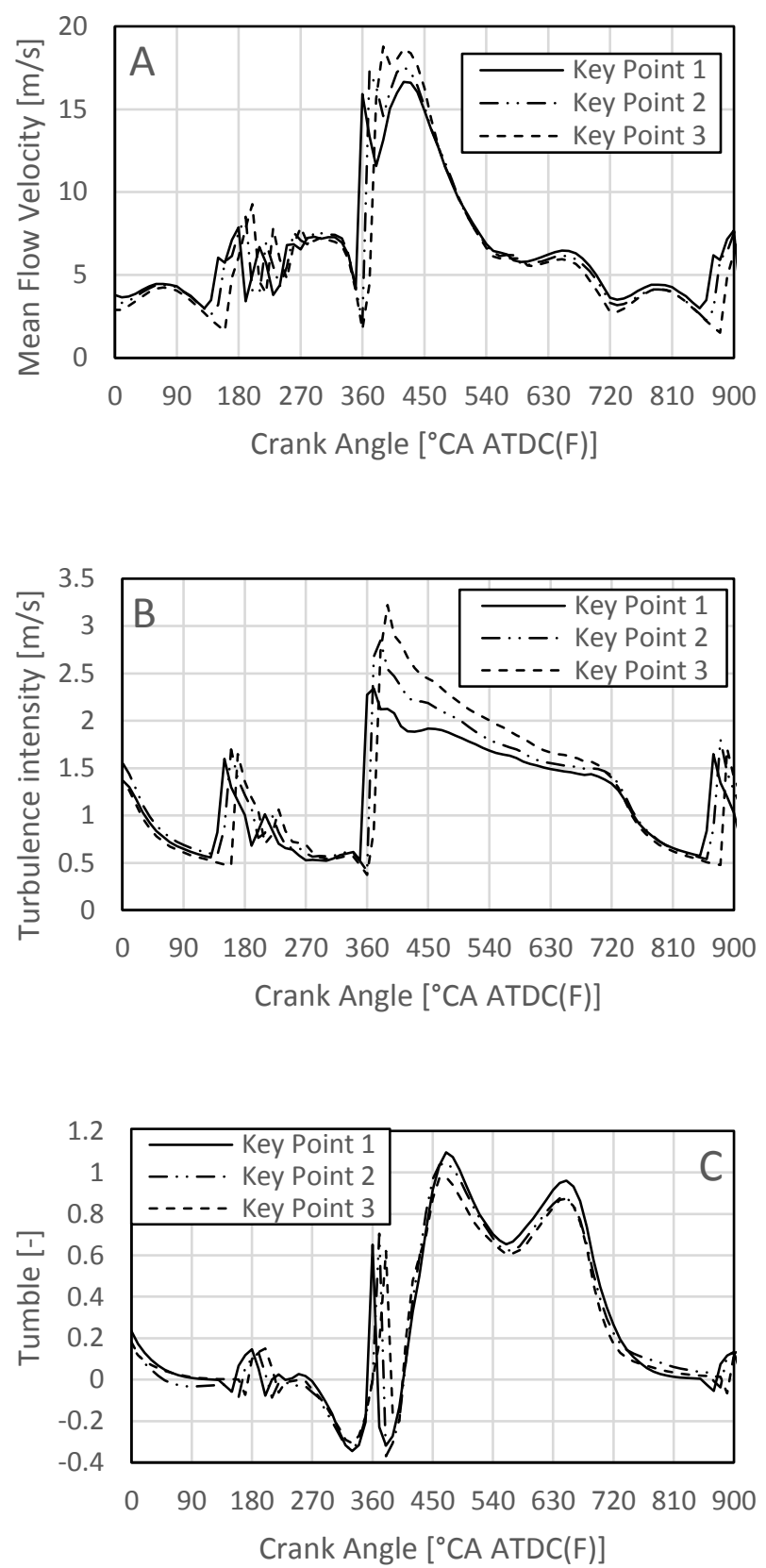

Figure 4: 3-D CFD prediction of different valve timings effect on in-cylinder mean flow velocity (graph A), turbulence intensity (graph B) and tumble ratio (graph C) 


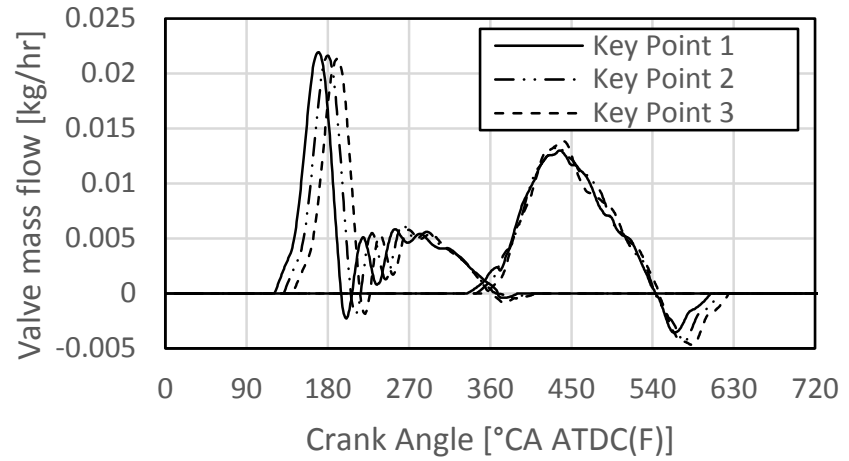

Figure 5: 1-D Intake and Exhaust mass flow for different valve timings
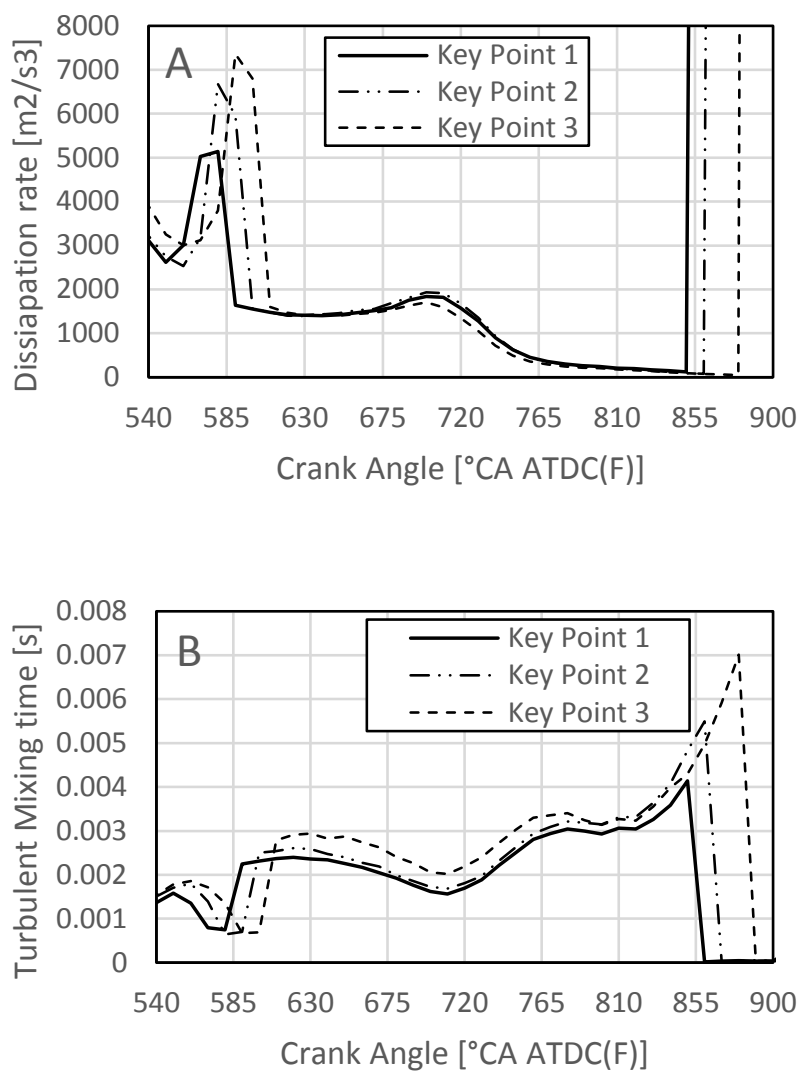

Figure 6: 3-D CFD prediction of different valve timings effect on the in-cylinder dissipation rate, $\varepsilon$ (graph $\mathbf{A}$ ) and the turbulent mixing time, $\tau_{t}$ (graph $\left.\mathbf{B}\right)$.

\section{Engine Speed Effect}

Figure 7 shows the main in-cylinder mass-averaged turbulence characteristics for different engine speeds at constant valve timing (Key points 1 and 24). Test data for Key Point 24 was not available. To investigate solely the effect of different engine speeds on the incylinder turbulence it was decided to carry out a 3-D CFD noncombusting calculation using Key point 1 valve timing with higher engine rotational speed. Results show increase in in-cylinder velocities with engine speed. These results are expected as the turbulence intensity is known to increase linearly with the engine speed $[10,12]$. The main reason for the mean in-cylinder flow velocity and $u$ ', to increase is due to increasing mean piston speed which result in higher 6 of 20 intake charge mass flow (see Figure 8). The effect of different engine speeds on the turbulent mixing time is shown in Figure 9. As expected Key Point 24 results in lower $\tau_{t}$ and thus in faster engine combustion rates [3].
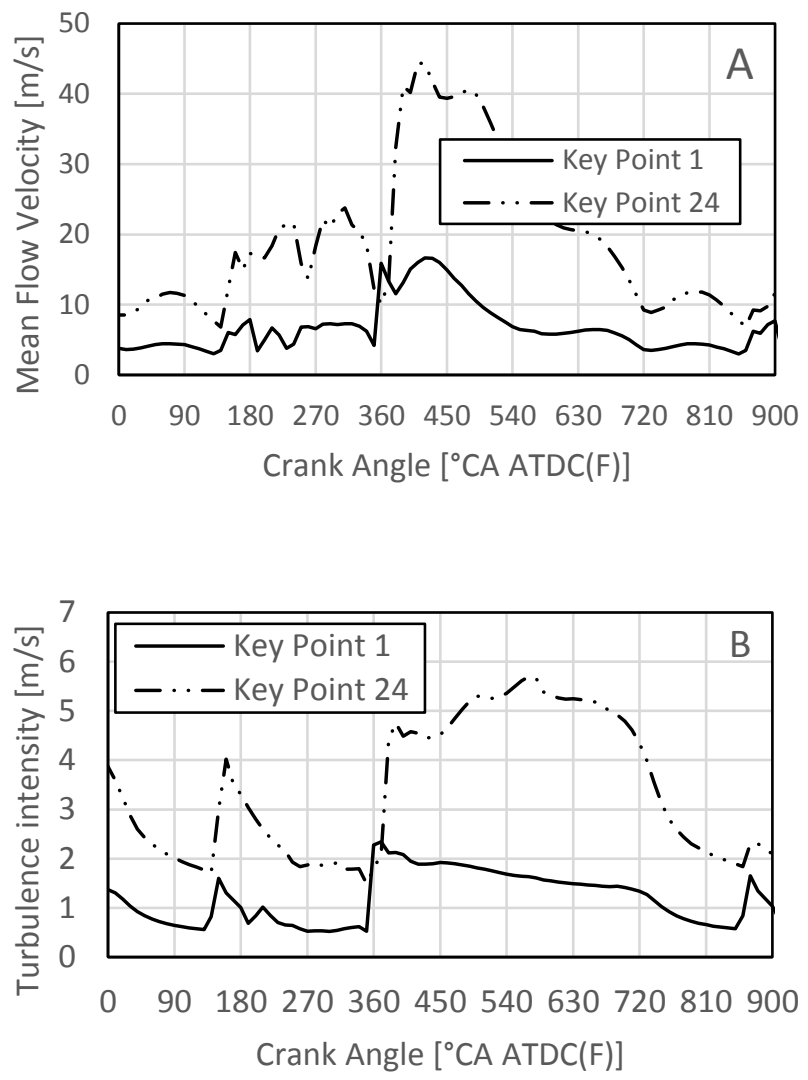

Figure 7: 3-D CFD prediction of different engine speeds effect on the in-cylinder mean flow velocity (graph A) and turbulence intensity (graph B)

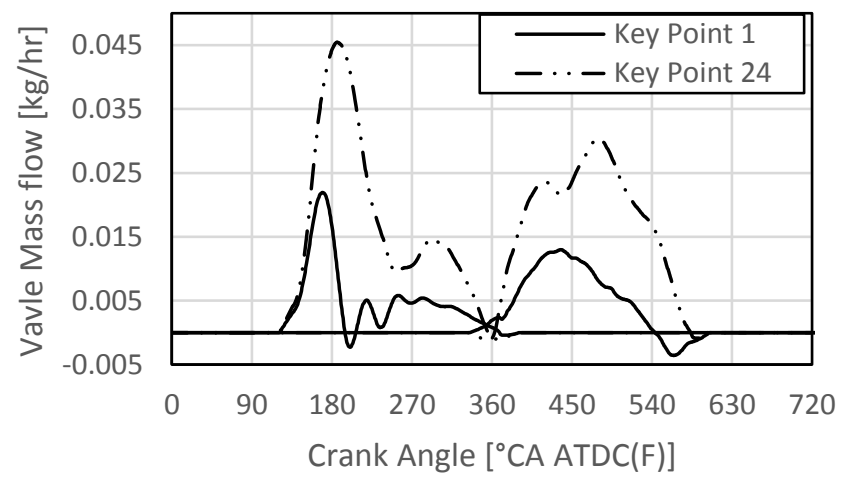

Figure 8: 1-D Intake and Exhaust mass flow for different engine speeds 


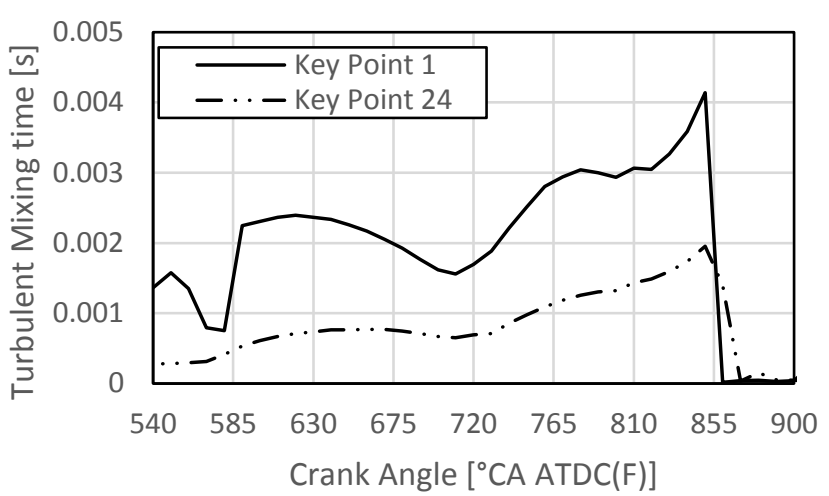

Figure 9: 3-D CFD prediction of different engine speeds effect on the Turbulent Mixing Time

\section{Scalar Mixing Time Response}

The SRM is based on the PDF approach applied to turbulent flows. It therefore requires an external turbulence input to set the frequency at which the PDF changes and to calculate the turbulent flame speed [5, $6,8,35,39]$. The SRM turbulence input, known as turbulent mixing time, can be experimentally derived or extracted from either 3-D CFD calculations or from simplified 0-D turbulence model and is defined as the ratio between the turbulent kinetic energy, $k$, and its dissipation rate, $\varepsilon$ (see Equation 3,Figure 6 and Figure 9). Due to the simplified nature of the 0-D SRM and to counterbalance the uncertainties stemming from the 3-D CFD calculations the turbulent mixing time calculated in Equation 3 needs to be scaled with the user input multiplier CsRMBaseline as explained in Equation 4. The CsRmBaseline was shown to be independent of the simulated engine operating condition and thus only a single baseline calibration to a single engine point is required [3].

In this work, multiple 3-D non-combustion CFD calculations have been carried out to analyze the effect of different valve timings and different engine speeds on the in-cylinder turbulence field. A turbulence correlation, relating the 1-D engine system changes in the intake port velocity to the scalar mixing time, $\tau_{S R M}$, in response to different operating conditions, was developed. The turbulent mixing time, $\tau_{t}$, derived from a single 3-D non-combusting CFD calculation was used to initially characterize the engine turbulence field. The developed correlation was used to predict the change in the turbulence, allowing the SRM to predict the engine RoHR at the explored conditions. The VVT analysis carried out with 3-D in-cylinder calculations showed that different valve timings influence the flow viscous stresses. Retarding the intake valve phasing and in particular the IVC timing, results in higher in-cylinder back flows due the piston moving toward TDC increasing the cylinder pressure. This reduces the resulting in-cylinder turbulence level during combustion due to higher energy being dissipated into heat suggested by the increased $\varepsilon$ generation at IVC. Higher turbulent mixing times, $\tau_{t}$, can therefore be related to late IVC timings. Further, the WAVE 1-D engine system model confirmed that further retarding the IVC timing from $540{ }^{\circ} \mathrm{CA}$ ATDC $(F)$ results in greater negative intake port velocity, (see Figure 5). This similarity across 1-D and 3-D CFD results can therefore be used to derive the $\tau_{S R M}$ response to different valve timings without the need of running time consuming CFD calculations at each of the explored timings. Moreover, different engine speeds influence the resulting in-cylinder bulk motion. The magnitude of this change can as well be related to the change in the intake port velocity. 1-D analysis can therefore be used to derive the external turbulent input required by the SRM combustion model.

7 of 20
Experimental data for Key Point 1 in Table 3, including burn angles, was used as basis to tune the WAVE 1-D model. In-cylinder conditions at IVC and fueling were extracted and used as inputs to calibrate the SRM model. The value of CSRMBaseline (see Equation 4) and the SRM ignition input were calibrated to match Key Point 1 burn angles and engine load. The spark kernel is not modelled in the SRM approach and thus the necessary SRM ignition input timing cannot be directly compared to the experimental spark timing and needs to be calibrated as explained in [3]. The initial CSRMBaseline and SRM ignition timing calibration was iteratively carried out to match the given engine load. Once the SRM was correctly calibrated the WAVE model valve timings were changed to replicate the VVT swing in Table 3 to successively extract IVC in-cylinder conditions for the SRM. The WAVE 1-D model needs a pre-defined engine burn rate to approximate the combustion and predict the necessary boundary condition, However, as the SRM and the 1-D WAVE model were not running simultaneously, the combustion rate needed to be defined to initialize the WAVE. Therefore, necessary pre-defined burn rates within the 1-D model were not adjusted for different valve timings. The scalar mixing time response to VVT was predicted using Equation 5 and Equation 6 which correlated the effect of different valve timings on the 1-D intake port velocity to in-cylinder scalar mixing time. Equation 5 integrates the intake port velocity between IVO and IVC. Retarded IVC timings correspond to smaller integral values compared to earlier IVC timings due to greater negative intake flows. Comparison between the turbulent mixing time and scalar mixing time profiles for different valve timings derived using Equation 5 and Equation 6 are shown in Figure 11. The most retarded IVC timing (Key Point 3) corresponds to the highest profile which confirms the 3-D CFD analysis results. The same physical based correlation was used to derive the effect of different engine speed on the scalar mixing time, Equation 7 and Equation 8. Increased engine speed would result in higher intake port velocity and thus a higher velocity integral for given intake valve phasing but different speed. As for the VVT swings, IVC boundary conditions for the SRM were extracted from the WAVE model. Expected burn angles values for the simulated engine speed were used to initialise the model.

$$
\tau_{t}=\frac{k}{\epsilon} \approx \frac{l_{l}}{u^{\prime}}
$$

With:

- $\quad k=$ turbulent kinetic energy, $\left[\mathrm{m}^{2} / \mathrm{s}^{2}\right]$

- $\varepsilon=$ turbulence dissipation rate, $\left[\mathrm{m}^{2} / \mathrm{s}^{3}\right]$

- $\quad l_{l}=$ integral length scale, $[\mathrm{m}]$

- $u^{\prime}=$ turbulence intensity, $[\mathrm{m} / \mathrm{s}]$

Equation 3: Turbulent Mixing time.

$$
\tau_{S R M}=\tau_{t} * C_{S R M_{\text {Baseline }}}
$$

Equation 4: Scalar mixing time.

$$
C_{S R M V V T_{i}}=\frac{\int_{I V O_{V V T_{i}}}^{I V C_{V V T_{i}}} \text { Intake Port Velocity }{ }_{V V T_{i}}}{\int_{I V O_{\text {Baseline }}}^{I V C_{\text {Baseline }}} \text { Intake Port Velocity }}
$$

Equation 5: Scalar Mixing time response to VVT

$$
\tau_{S R M_{i}}=\frac{\left(\tau_{t_{\text {Baseline }}} * C_{S R M_{\text {Baseline }}}\right)}{C_{S R M_{V V T i}}}
$$

Equation 6: Scalar Mixing time for different VVT 


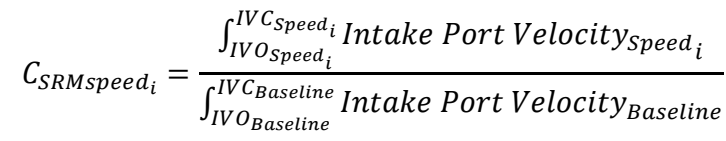

Equation 7: Scalar Mixing time response to Engine Speed

$$
\tau_{S R M_{i}}=\frac{\left(\tau_{t_{\text {Baseline }}} * C_{S R M_{\text {Baseline }}}\right)}{\left(C_{\text {SRM }_{\text {Speed }_{i}}}\right)}
$$

Equation 8: Scalar Mixing time for different Engine Speed

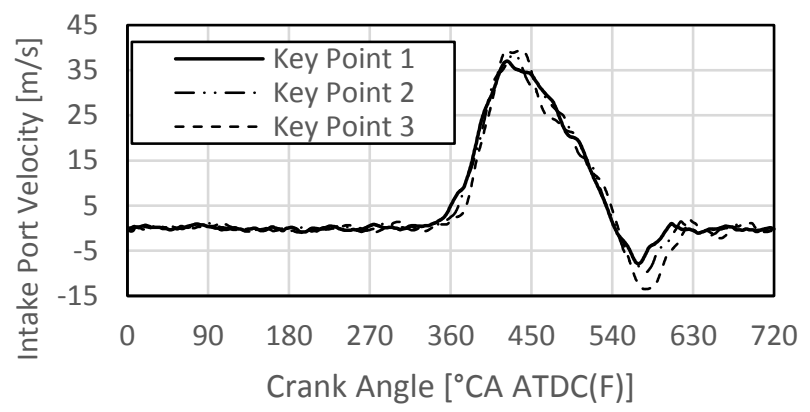

Figure 10: VVT effect on the 1-D Intake Port Velocity

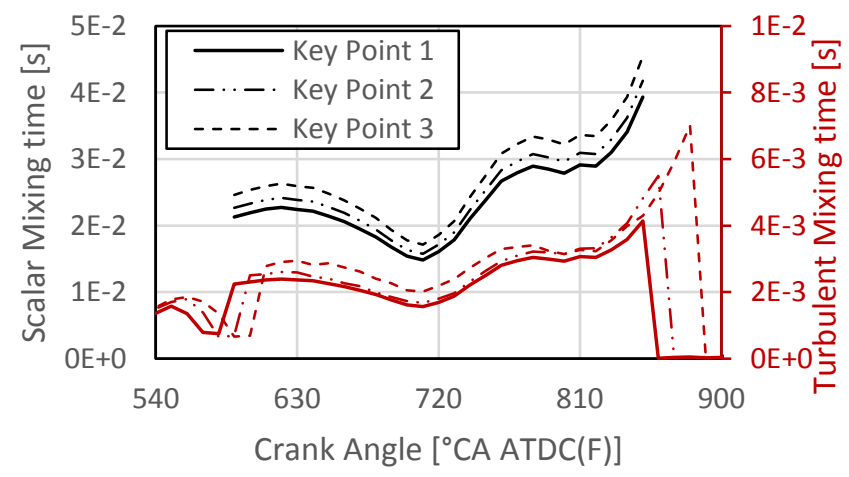

Figure 11: Predicted scalar mixing time profiles, $\tau_{\mathrm{SRM}}$ (left axis) vs $3 \mathrm{D}$ CFD predicted turbulent mixing time profiles, $\tau_{t}$ (right axis) for different valve timings.

\section{Combustion Predictions Comparison with Experimental Data}

The turbulent mixing time, $\tau_{t}$, from Key Point 1 was used as baseline to derive the scalar mixing time, $\tau_{\mathrm{SRM}}$, for the other experimental key points in Table 3. The chosen turbulent mixing time, extracted from a single non-combusting 3-D CFD calculation, was only scaled according to the simulated operating condition using Equation 5, Equation 6, Equation 7 and Equation 8.

In this section a valve timing swing and EGR swing for a given engine speed, and the engine speed effect on the RoHR are shown. RoHR predictions of the remaining Key Points can be found in the Appendix.

\section{Methodology assessment criteria}

Combustion results obtained from the presented methodology were assessed using the following two metrics.
Firstly, predicted burn angles were compared to experimental (averaged) values and expected to fall within the experimental standard deviation calculated using Equation 1. Black error bands, showing the experimental standard variation, are applied to all the figures. Secondly, to make a more rigorous assessment of the feasibility of the methodology, a more restrictive metric was set. A burn angle prediction confidence interval of $\pm 2{ }^{\circ} \mathrm{CA}$ from the experimental (averaged) data is expected to consider this methodology an applicable solution during the initial hardware screening phase of engine development. Predicted burn angles were therefore assessed against this target. Red error bands, representing the $\pm 2{ }^{\circ} \mathrm{CA}$ confidence interval, are applied to all figures.

\section{Validation for Different Valve timings}

The experimental data used for this study was characterized by small valve timings adjustments, for given engine speed and load. Relatively small changes in the predicted 3-D CFD bulk turbulence characteristics and 1-D intake port velocity profiles were observed for different valve timings (see the "Variable Valve Timing Effect on InCylinder Turbulence" section). Despite this, the developed methodology successfully discriminated the engine burn rate for different valve timings. Moreover, the experimental data used for this study was acquired over a two days test campaign aimed to optimize engine valves phasing. The influence of others external parameters, (e.g. hardware replacements), and possible experimental sources, (e.g. sensors re-calibration), on the observed burn angles can therefore be considered minimised. Predicted burn angle results for different valve timings with a constant engine speed are shown in Figure 12 and Figure 13. The presented results model the experimental engine conditions for Key Points 1,2 and 3. Results showed that a single baseline calibration (Key point1) together with the developed turbulence response allowed good prediction of engine combustion rate at different engine operating points. Burn angle prediction fell both: within the experimental standard deviation and the set $\pm 2{ }^{\circ} \mathrm{CA}$ confidence interval. IVC boundary conditions and fueling input were extracted from the WAVE model. The model was tuned using test data from Key Point 1. Predefined burn angles necessary to initialize the model were left constant and equal to Key point 1 . Equation 5 and Equation 6 were used to define the scalar mixing time, $\tau_{\text {SRM, }}$ according to the simulated key point. Figure 12 shows a difference between the experimental spark and the chosen SRM ignition timings of $7-10$ ${ }^{\circ} \mathrm{CA}$. The SRM ignition time is a user-defined input physically corresponding to the crank angle at which the flame kernel is fully developed, and actual flame front starts propagating. The procedure to set the SRM ignition time, presented in [3], was used to make a rigorous comparison to experimental data where the approximate spark timing is known. Once all other model inputs are fixed, adjusting the SRM ignition time will affect the predicted engine burn rate and the total energy output. The model was therefore calibrated to achieve the experimental engine loads, gradually retarding the SRM ignition time from the experimental spark. The difference between spark and SRM ignition timings can be referred to the mixture ignition delay period. Results in Figure 12 are comparable to experimental ignition delays found in [45] for similar engine operating conditions. Results show that the SRM ignition timing for a case with a retarded IVC timing, such as Key Point 3, compared to the chosen baseline IVC timing (Key point 1), had to be advanced to keep the load constant for different valve strategies. Retarded IVC timings, as shown by the 3-D CFD analysis, result in higher turbulent mixing time profiles, $\tau_{t}$, due to higher viscous stresses. Thus, following Equation 5 and Equation 6, higher $\tau_{S R M}$ 's are related to late IVC timings and result in slower combustion rates.

The chosen ignition timings in Figure 12 result in good agreement with the experimental CA50 and the burn duration CA10-90, as show in 
Figure 13. Results in Figure 12 shows a slight discrepancy between the experimental spark timing and the SRM ignition timing at Key Point 3, likely due to experimental uncertainties. For Key Point 3, spark timing was retarded by about $2{ }^{\circ} \mathrm{CA}$ compared to the spark timing of Key Point 1 . Nevertheless, the retarded spark timing resulted in a shorter experimental CA10-90 for Key Point 3 compared to Key Point 1, Figure 13b. Key Point 3 SRM ignition timing was instead advanced by $1{ }^{\circ} \mathrm{CA}$ compared to the baseline case and resulted in a shorter combustion duration. A good in-cylinder pressure match for all investigated key points was achieved. The initial multiplier in Equation 4, CSRM, was calibrated to match Key point 1 engine load and the average in-cylinder pressure. The engine combustion rates predicted by the 0-D SRM combustion model should be fed back in the WAVE model to correctly predict the overall engine performance as shown in Figure 1. Nevertheless, since this work only focused on the turbulence response development and 0-D SRM predictive capability assessment an automated procedure to feedback the predicted RoHR has yet to be implemented. Predicted results show that the assumed correlation between intake port velocity and $\tau_{\mathrm{SRM}}$ is valid for the explored conditions.

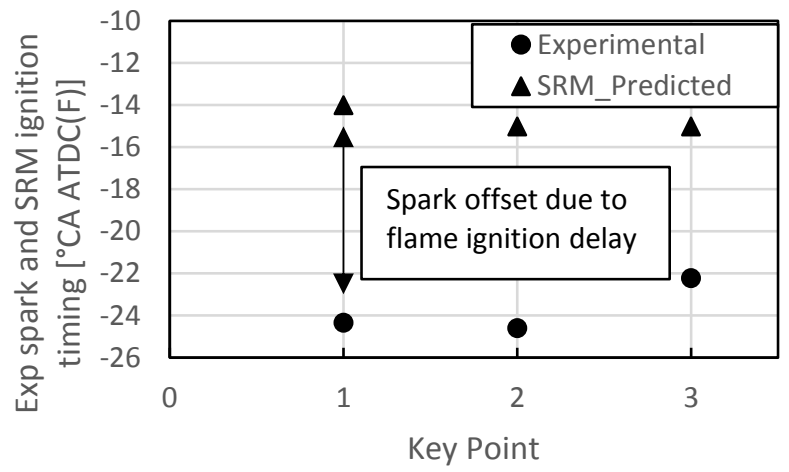

Figure 12: Experimental spark and SRM input timings comparison for different valve timings
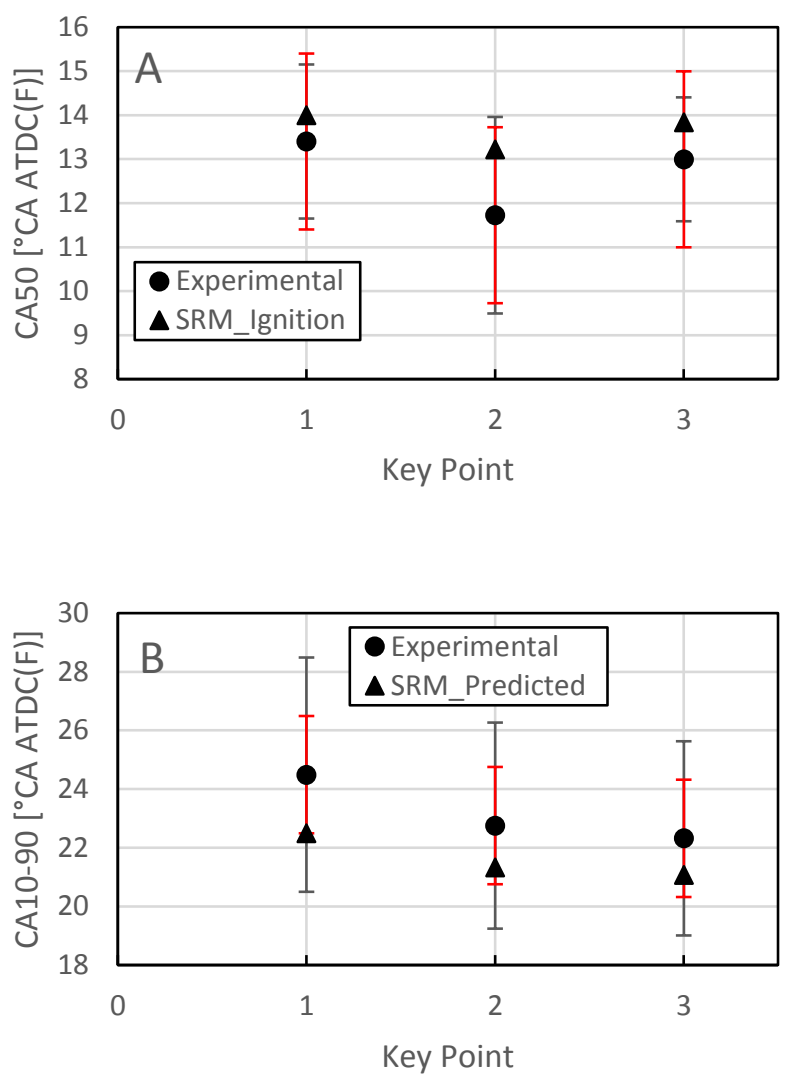

Figure 13: Predicted and experimental CA50 (graph A) and burn duration, CA10-90 (graph B) for different valve timings. Black error bands represent the experimental standard deviation. The $\pm 2{ }^{\circ} \mathrm{CA}$ confidence interval from experimental (averaged) values is shown by red error bands.

\section{Validation for Charge Dilution}

The predicted burn duration response to charge dilution (EGR rate) for a given constant engine speed and valve timing are shown in Figure 14. The experimental engine conditions for Key Point 4, 5, 6 and 7 in Table 3, were modeled. RoHR prediction for other EGR swings can be found in the Appendix. Reported EGR rates refer to total EGR rates extracted from the WAVE model together with the IVC boundary conditions and fueling. The WAVE model predefined burn angles necessary to initialize the model, were left constant and equal to Key Point 1 . The 1-D analysis showed that the intake port velocity is not significantly affected by different EGR rates. The scalar mixing time for different charge dilutions was therefore only derived once for the given valve timings using Equation 5 and Equation 6. As expected, predicted results show that higher EGR ratios result in longer burn durations, CA10-90, Figure 14. The experimental spark timings for different EGR rates were adjusted to keep the CA50 angle constant as shown in Figure 15. The SRM ignition timings also had to be adjusted accordingly to the simulated operating point since all the others model inputs were fixed. As greater EGR rates result in longer burn durations, the SRM ignition timing had to be advanced accordingly, to keep CA50 close to a constant value and to match the desired engine load. A discrepancy between the SRM ignition and the spark timings at Key point 5, likely due to experimental uncertainties, is shown in Figure 15. For Key point 5 , spark timing was retarded by about $1{ }^{\circ} \mathrm{CA}$ compared to Key point 4 whilst the EGR rate was lowered. Nevertheless, the retarded spark timing and lower EGR ratio resulted in a similar experimental CA 10-90 for Key point 5 compared to Key point 4 (see Figure 14). Calculated CA50 angles show a maximum 
difference of about $1{ }^{\circ} \mathrm{CA}$ between the highest and the lowest EGR rate. CA50 angles Key Points 6 and 7 resulted outside the experimental standard deviation (see the Appendix). Nevertheless, predictions fell within the $\pm 2{ }^{\circ} \mathrm{CA}$ confidence interval. In-cylinder pressure traces were found to match for all the explored cases confirming that the EGR effect on the in-cylinder bulk turbulent motion and thus on $\tau_{\mathrm{SRM}}$ is not significant for a correct engine combustion rate prediction

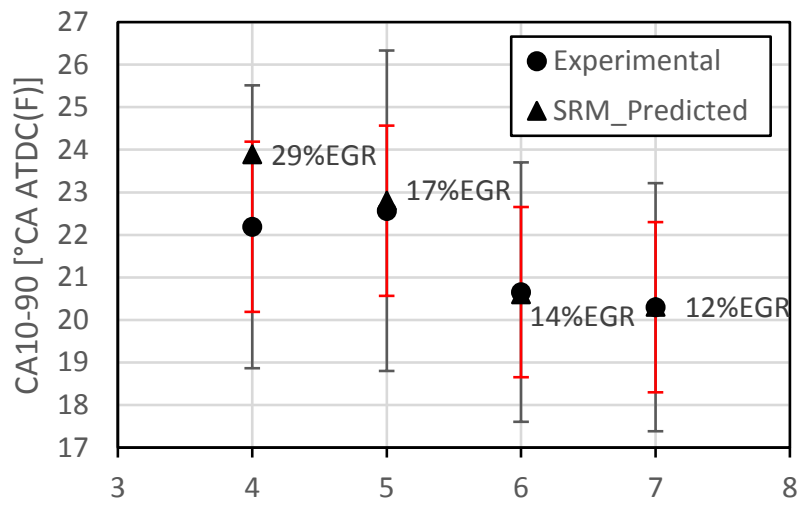

Figure 14: Predicted and experimental burn duration, CA10-90 for different charge dilution. Black error bands represent the experimental standard deviation. The \pm 2 ${ }^{\circ} \mathrm{CA}$ confidence interval from experimental (averaged) values is shown by red error bands.

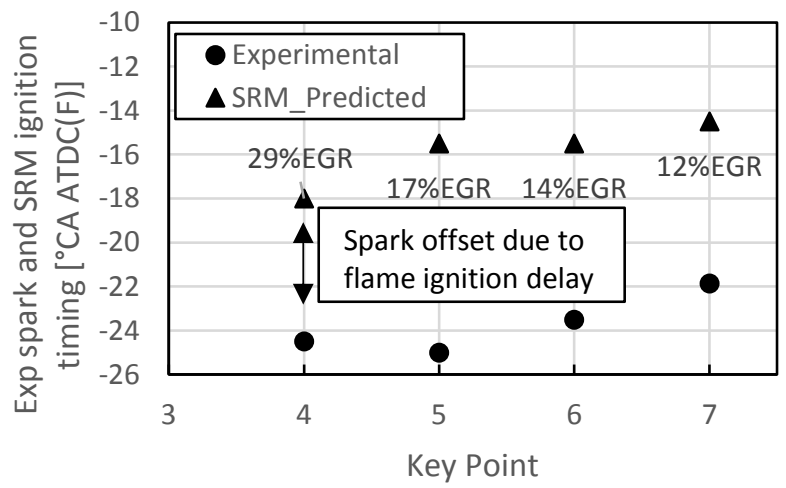

Figure 15: Experimental spark and SRM input timings comparison for differnte charge dilutions

\section{Validation for Engine Speeds}

Predicted burn angles are shown in Figure 16. The experimental engine conditions for Key Points 3,11 16 and 21 were modeled. IVC boundary conditions and fueling were extracted from the WAVE model. Equation 5, Equation 6, Equation 7 and Equation 8 were used to derive the scalar mixing time response, $\tau_{S R M}$, to different engine speeds and valve timings. The difference between the experimental spark timing and the SRM ignition timing for different engine speeds is shown in Figure 17. SRM ignition timings followed a similar trend to the experimental spark timings with a constant difference between the two values of around $7.5^{\circ} \mathrm{CA}$ for all the investigated speeds but $3500 \mathrm{rev} / \mathrm{min}$ which was $5.5{ }^{\circ} \mathrm{CA}$. The SRM ignition time at 3500 $\mathrm{rev} / \mathrm{min}$ (Key Point 16) had to be further advanced to match the targeted engine load. This earlier SRM ignition timing resulted in an early CA10 prediction falling outside the experimental standard deviation and the $\pm 2{ }^{\circ} \mathrm{CA}$ interval. The effect of advanced ignition timing for Key Point 16 can also be seen for the CA10-90 prediction. 10 of 20
As all the burn angles but CA10 fall within the experimental deviation, the resulting CA10-90 at $3500 \mathrm{rev} / \mathrm{min}$ shows a longer combustion duration due to a shorter ignition delay (CA10) compared to test data. Predicted burn angle results for different engine speeds and in-cylinder pressure traces are available in the Appendix. Results for different speeds and valve timings show good agreement with test data suggesting that the assumed correlation between intake port velocity and $\tau_{S R M}$ is valid at the explored engine conditions.
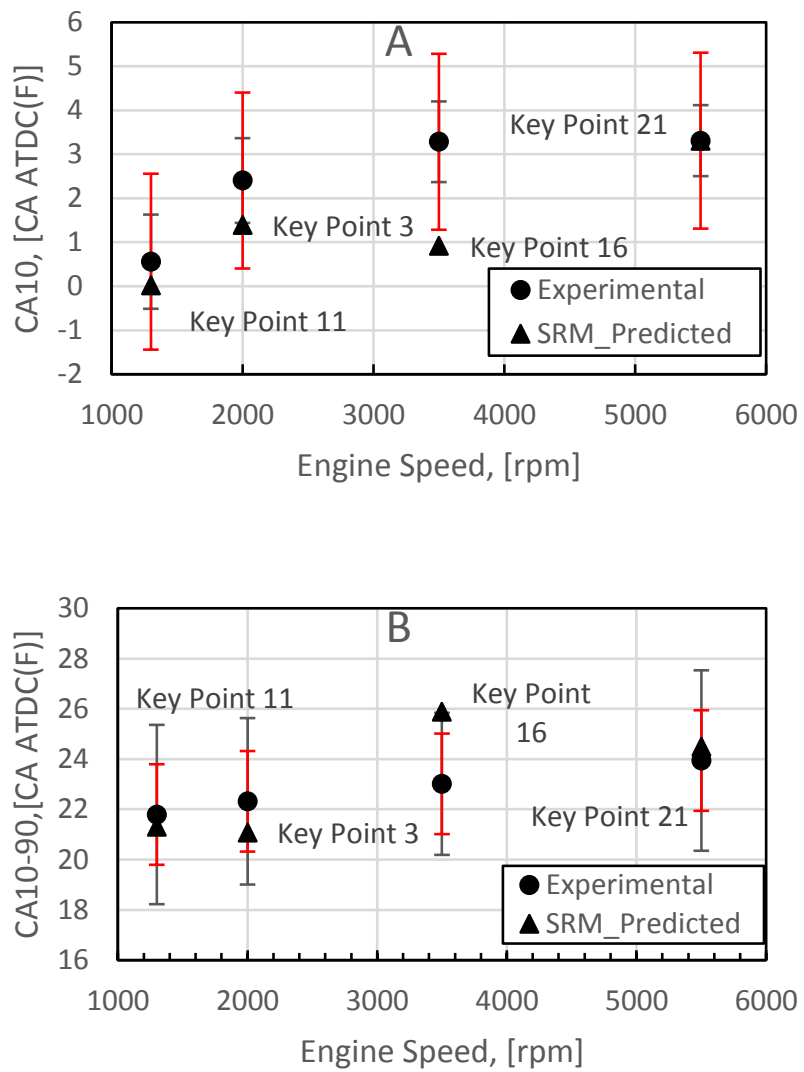

Figure 16: Predicted and experimental CA10 (graph A) and CA10-90 (graph B) for different engine speeds and valve timings. Black error bands represent the experimental standard deviation. The $\pm 2{ }^{\circ} \mathrm{CA}$ confidence interval from experimental (averaged) values is shown by red error bands.

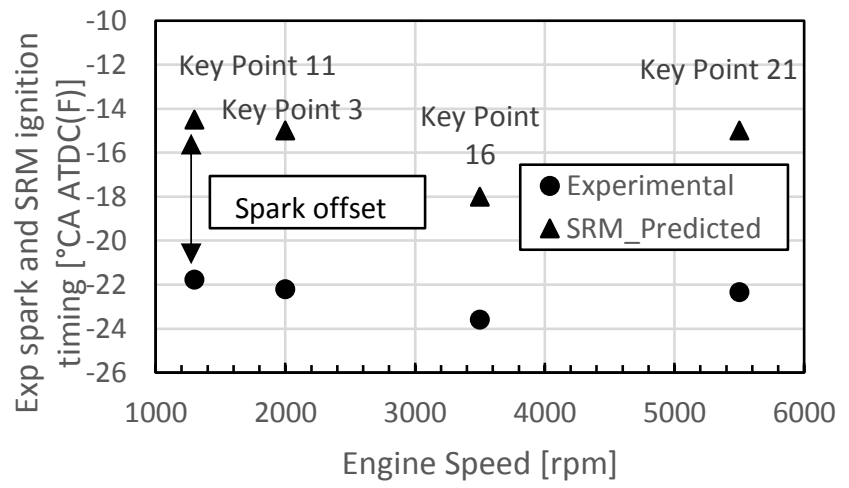

Figure 17: Experimental spark and SRM input timings comparison for different engine speeds and valve timings. Data labels refer to table 3 


\section{Conclusions}

The goal of providing reliable prediction of heat release rates at the early stages of development for gasoline engines, has led to a new process proposed, which incorporates 1-D and 3-D CFD tools with a Q-D SRM. We have continued to evaluate the process and have now shown that it was possible to achieve this goal for cases at different engine speeds where valve timing and charge dilution were the driving parameters

3-D CFD calculations were used to produce in-cylinder turbulent mixing time characteristic profiles, which are key inputs to the SRM. Crucially, it was shown that the turbulent characteristics are bound only to the given engine geometry itself, i.e. the turbulent mixing time profile did not change with the different engine operating criteria explored, e.g. valve timing, for that hardware. However, a change in the magnitude of the average turbulent mixing time in response to the operating condition was observed.

This change in the average turbulent mixing time was then related to a physical parameter, the intake port velocity. A simple scaling factor response based on this was developed to manipulate the characterized in-cylinder turbulence for a given engine geometry. Using this response as an input to the SRM combustion model enabled the engine burn rate to be predicted within $\pm 2{ }^{\circ} \mathrm{CA}$ of the experimental (averaged) data for different valve timings. Further, it was shown the SRM responded realistically to changes in engine speed and charge dilution (EGR).

\section{References}

1. Stone, R., Introduction to internal combustion engines. 1985: Macmillan.

2. Heywood, J.B., Internal combustion engine fundamentals. 1988: New York : McGraw-Hill, [1988] ()1988.

3. Rota, C., et al., Implementation of a New Predictive OD/1D/3D Process for the Heat Release Prediction of a Gasoline Engine in the Early Development Stage. 2019, SAE International.

4. Versteeg, H. and W. Malalasekera, An introduction to computational fluid dynamics : the finite volume method $/ \mathrm{H}$. K. Versteeg and W. Malalasekera. 2018.

5. $\quad$ Kraft, M., Stochastic Modeling of Turbulent Reacting Flow in Chemical Engineering. 1998: VDI Verlag.

6. $\quad$ Kraft, M., et al., Investigation of combustion emissions in a homogeneous charge compression injection engine: Measurements and a new computational model. Proceedings of the Combustion Institute, 2000. 28(1): p. 1195-1201.

7. Tunér, M., et al., A PDF-Based Model for Full Cycle Simulation of Direct Injected Engines. 2008, SAE International

8. $\quad$ Bjerkborn, S., et al., A Monte Carlo Based Turbulent Flame Propagation Model for Predictive SI In-Cylinder Engine Simulations Employing Detailed Chemistry for Accurate Knock Prediction. SAE International Journal of Engines, 2012. 5(4): p. 1637-1647.

9. Verhelst, S. and C.G.W. Sheppard, Multi-Zone thermodynamic modelling of spark-ignition engine combustion-overview. Vol. 50. 2009. 1326-1335.

10. Bozza, F., et al., Refinement of a OD Turbulence Model to Predict Tumble and Turbulent Intensity in SI Engines. Part I: 3D Analyses. 2018, SAE International.

11. Bozza, F., et al., Refinement of a OD Turbulence Model to Predict Tumble and Turbulent Intensity in SI Engines.
Part II: Model Concept, Validation and Discussion. 2018, SAE International.

12. De Bellis, V., et al., Hierarchical 1D/3D Approach for the Development of a Turbulent Combustion Model Applied to a VVA Turbocharged Engine. Part I: Turbulence Model. Energy Procedia, 2014. 45: p. 829-838.

13. De Bellis, V., et al., Hierarchical 1D/3D Approach for the Development of a Turbulent Combustion Model Applied to a VVA Turbocharged Engine. Part II: Combustion Model. Energy Procedia, 2014. 45: p. 1027-1036.

14. Perini, F., F. Paltrinieri, and E. Mattarelli, A quasidimensional combustion model for performance and emissions of SI engines running on hydrogen-methane blends. International Journal of Hydrogen Energy, 2010. 35(10): p. 4687-4701

15. Blizard, N.C. and J.C. Keck, Experimental and Theoretical Investigation of Turbulent Burning Model for Internal Combustion Engines. 1974, SAE International.

16. Bozza, F., et al., Validation of a Fractal Combustion Model through Flame Imaging. 2005, SAE International.

17. Bray, K.N.C., Turbulent Combustion. By NORBERT PETERS. Cambridge University Press, 2000. 320 pp. ISBN 0521 60823. Journal of Fluid Mechanics, 2001. 426: p. $407-$ 409.

18. Peters, N., Fifteen lectures on laminar and turbulent combustion. Ercoftac Summer School, 1992. 1428.

19. Bücker, I., et al., Stereoscopic multi-planar PIV measurements of in-cylinder tumbling flow. Experiments in Fluids, 2012. 53(6): p. 1993-2009.

20. Bücker, I., et al., Engine In-Cylinder Flow Control via Variable Intake Valve Timing. 2013, SAE International.

21. Poulos, S.G. and J.B. Heywood, The Effect of Chamber Geometry on Spark-Ignition Engine Combustion. 1983, SAE International.

22. Millo, F., et al., Numerical and experimental investigation on combustion characteristics of a spark ignition engine with an early intake valve closing load control. Fuel, 2014. 121: p. 298-310.

23. Huang, R.F., et al., In-cylinder tumble flows and performance of a motorcycle engine with circular and elliptic intake ports. Experiments in Fluids, 2009. 46(1): p. 165-179.

24. Morel, T. and N.N. Mansour, Modeling of Turbulence in Internal Combustion Engines. 1982, SAE International.

25. Borgnakke, C., V.S. Arpaci, and R.J. Tabaczynski, A Model for the Instantaneous Heat Transfer and Turbulence in a Spark Ignition Engine. 1980, SAE International.

26. Bossung, C., et al. A quasi-dimensional charge motion and turbulence model for engine process calculations. in 15. Internationales Stuttgarter Symposium. 2015. Wiesbaden: Springer Fachmedien Wiesbaden.

27. Dulbecco, A., et al., Development of a Quasi-Dimensional $K-k$ Turbulence Model for Direct Injection Spark Ignition (DISI) Engines Based on the Formal Reduction of a 3D CFD Approach. 2016, SAE International.

28. Lafossas, F.A., et al., Application of a New 1D Combustion Model to Gasoline Transient Engine Operation. 2005, SAE International.

29. Grasreiner, S., et al., A quasi-dimensional model of turbulence and global charge motion for spark ignition engines with fully variable valvetrains. Vol. 15. 2014. 805816.

30. Fogla, N., et al., Development of a $K-k-\varepsilon$ Phenomenological Model to Predict In-Cylinder Turbulence. Vol. 10. 2017. 562-575. 
31. Franken, T., et al., Advanced Predictive Diesel Combustion Simulation Using Turbulence Model and Stochastic Reactor Model. 2017, SAE International.

32. Bernard, G., et al., Application of the SRM Engine Suite over the Entire Load-Speed Operation of a U.S. EPA Tier 4 Capable IC Engine. 2016, SAE International.

33. Lai, J., et al., Evaluating Emissions in a Modern Compression Ignition Engine Using Multi-Dimensional PDF-Based Stochastic Simulations and Statistical Surrogate Generation. 2018, SAE International.

34. Pasternak, M., et al., OD/3D Simulations of Combustion in Gasoline Engines Operated with Multiple Spark Plug Technology. 2015, SAE International.

35. Pasternak, M., et al., Gasoline engine simulations using zero-dimensional spark ignition stochastic reactor model and three-dimensional computational fluid dynamics engine model. International Journal of Engine Research, 2016. 17(1): p. 76-85.

36. Software, R., VECTIS Manual V.2016.2. 2016.

37. Nsikane, D.M., et al., Statistical Approach on Visualizing Multi-Variable Interactions in a Hybrid Breakup Model under ECN Spray Conditions. SAE International Journal of Engines, 2017. 10(5): p. 2461-2477.

38. Software, R., WAVE Manual V.2016.2. 2016.

39. Pope, S.B., PDF methods for turbulent reactive flows. Progress in Energy and Combustion Science, 1985. 11(2): p. 119-192.

40. Yang, B. and S.B. Pope, An investigation of the accuracy of manifold methods and splitting schemes in the computational implementation of combustion chemistry. Combustion and Flame, 1998. 112(1): p. 16-32.

41. LOGESoft, Engine Models Manual Book, LogeSoft. 2016.

42. Gogan, A., et al., Stochastic Model for the Investigation of the Influence of Turbulent Mixing on Engine Knock. 2004, SAE International.

43. Janicka, J., W. Kolbe, and W. Kollmann, Closure of the Transport Equation for the Probability Density Funcfion of Turbulent Scalar Fields, in Journal of Non-Equilibrium Thermodynamics. 1979. p. 47.

44. Curl, R.L., Dispersed phase mixing: I. Theory and effects in simple reactors. AIChE Journal, 1963. 9(2): p. 175-181.

45. Thoo, W.J., et al., Characterisation of ignition delay period for a compression ignition engine operating on blended mixtures of diesel and gasoline. Applied Thermal Engineering, 2014. 66(1): p. 55-64.

\section{Acknowledgment}

The authors would like to thank the directors of Ricardo plc for permission to publish this paper. We would also like to acknowledge the significant technical contributions to the work made by Andrew Ward and James Mullineux, from Ricardo UK. We would like to thank Ricardo UK, and the University of Brighton, for funding this EngD project. Finally, we extend our special thanks to Fabian Mauss from LOGE for the fruitful cooperation and for providing free software licenses.

\section{Nomenclature}

\begin{tabular}{|l|l|}
\hline ATDC(F) & After Top Dead Centre (firing) \\
\hline BDC & Bottom Dead Centre \\
\hline
\end{tabular}

\begin{tabular}{|c|c|}
\hline BMEP & Brake Mean Effective Pressure \\
\hline $\mathrm{BTDC}(\mathrm{F})$ & Before Top Dead Centre (firing) \\
\hline $\mathrm{CA}$ & Crank Angle \\
\hline CA $10-90$ & Burn Duration \\
\hline CA10 & Crank Angle 10\% Mass Fraction Burned \\
\hline CA50 & Crank Angle 50\% Mass Fraction Burned \\
\hline CA90 & Crank Angle $90 \%$ Mass Fraction Burned \\
\hline CFD & Computational Fluid Dynamic \\
\hline EGR & Exhaust Gas Recirculation \\
\hline EVC & Exhaust Valve Closing \\
\hline EVO & Exhaust Valve Opening \\
\hline G-ISFC & Gross Indicated Specific Fuel Consumption \\
\hline IVC & Intake Valve Closing \\
\hline IVO & Intake Valve Opening \\
\hline$k$ & Turbulent Kinetic Energy \\
\hline$l_{l}$ & Integral length scale \\
\hline MBT & Minimum advance for Best Torque \\
\hline MFB & Mass Fraction Burn \\
\hline PDF & Probability Density Function \\
\hline RANS & Reynold Averaged Navier Stokes \\
\hline RoHR & Rate of Heat Release \\
\hline SRM & Stochastic Reactor Model \\
\hline TDC & Top Dead Centre \\
\hline$u^{\prime}$ & Turbulence Intensity \\
\hline VVT & Variable Valve Timing \\
\hline$\varepsilon$ & Turbulent Dissipation Rate \\
\hline$\mu_{t}$ & Turbulent Viscosity \\
\hline$\tau_{S R M}$ & Scalar Mixing Time \\
\hline$\tau_{t}$ & Turbulent Mixing Time \\
\hline
\end{tabular}




\section{Appendix}

\section{0rev/min VVT Combustion Prediction}
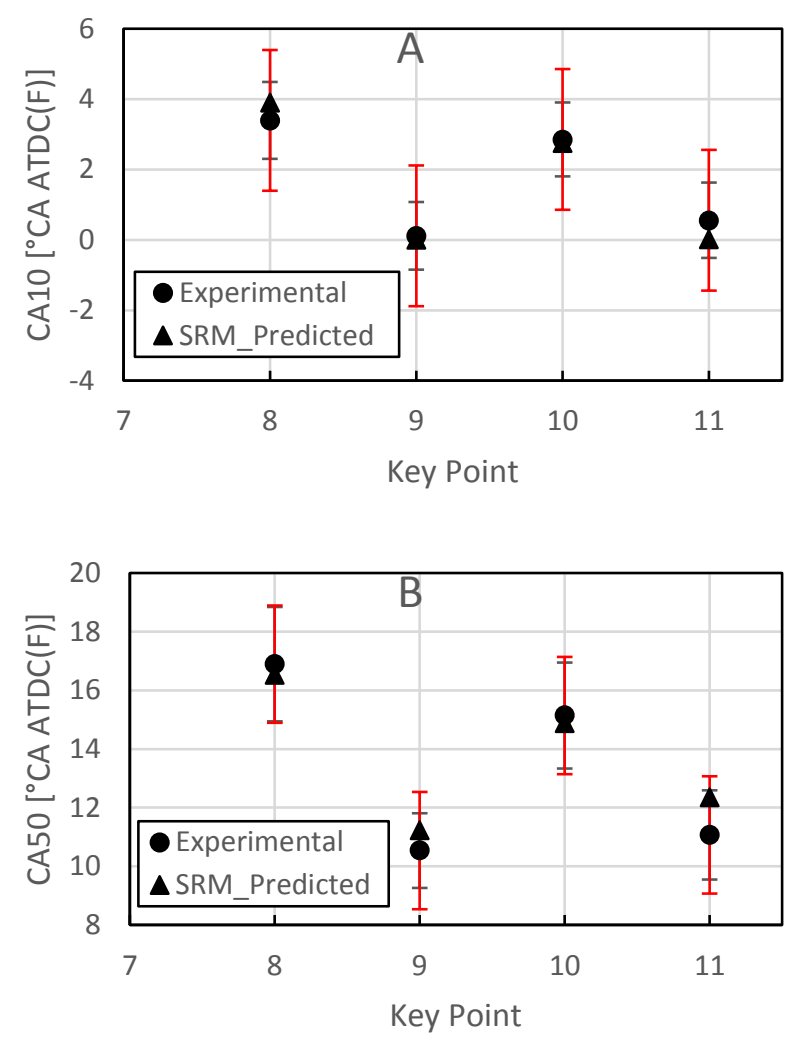
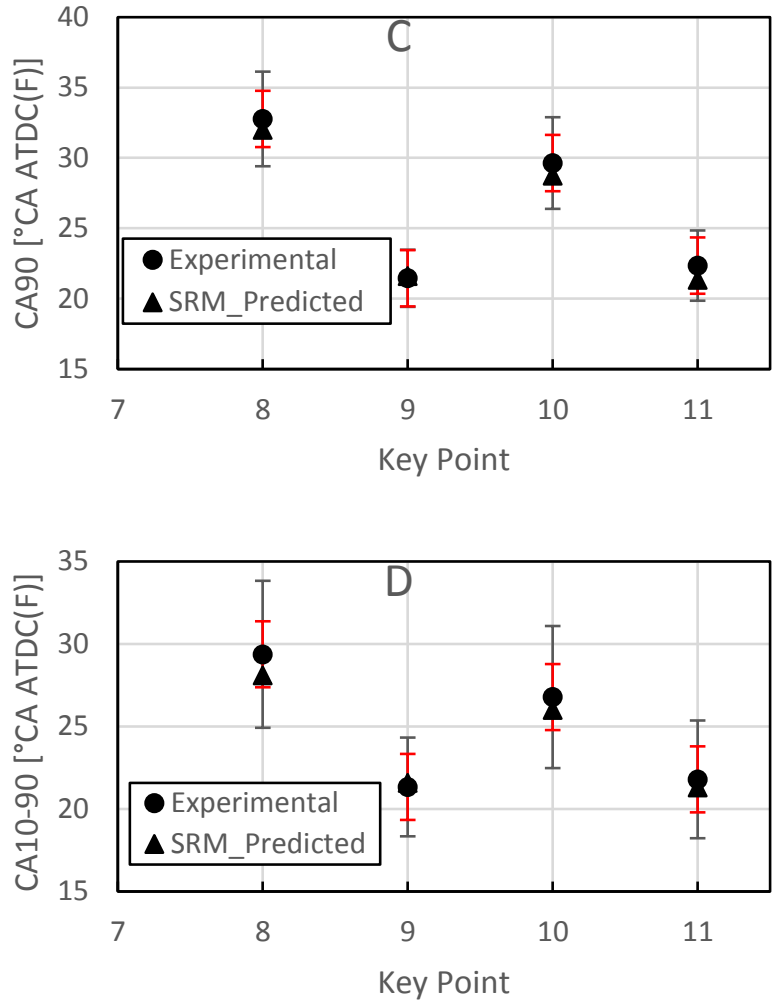

Figure 18: Predicted and Experimental CA10 (graph A), CA50 (graph B) (graph C) and CA10-90 (graph D) for different valve timings. Black error bands represent the experimental standard deviation. The $\pm 2{ }^{\circ} \mathrm{CA}$ confidence interval from experimental (averaged) values is shown by red error bands.

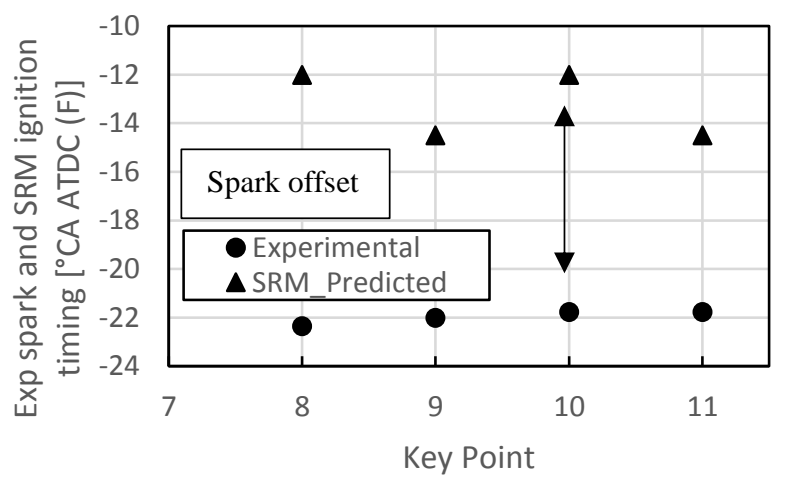

Figure 19: Experimental spark and SRM input timings comparison for different valve timings 

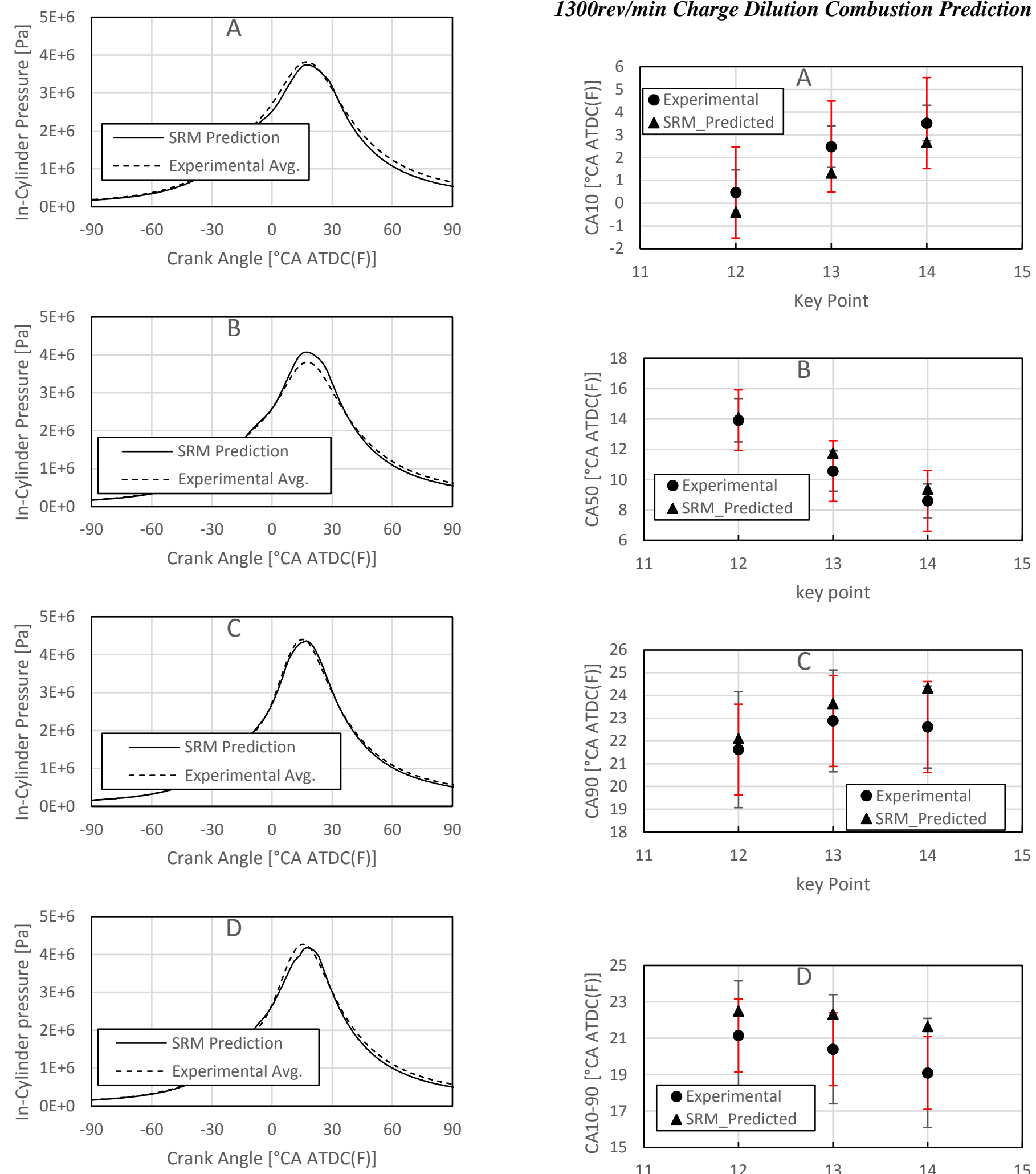

Figure 20: Predicted pressure and experimental pressure traces for key point 8 (graph A), key point 9 (graph B), key point 10 (graph C) and key point 11 (graph D)

Figure 21: Predicted and Experimental CA10 (graph A), CA50 (graph B) (graph C) and CA10-90 (graph D) for different charge dilution. Black error bands represent the experimental standard deviation. The $\pm 2{ }^{\circ} \mathrm{CA}$ confidence interval from experimental (averaged) values is shown by red error bands. 


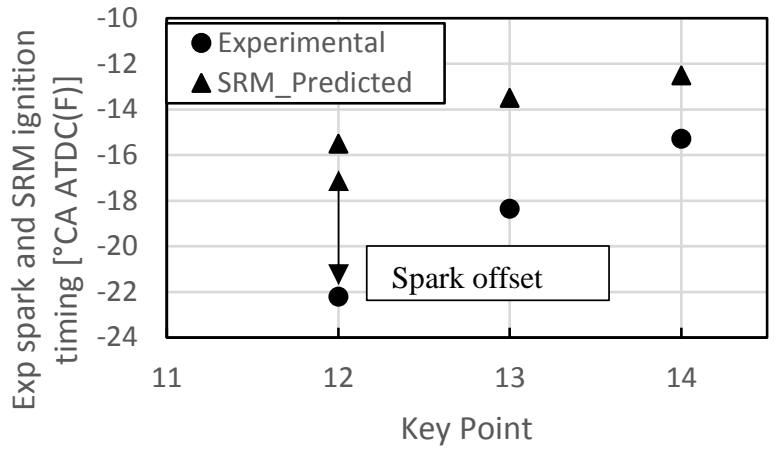

Figure 22: Experimental spark and SRM input timings comparison for different charge dilution
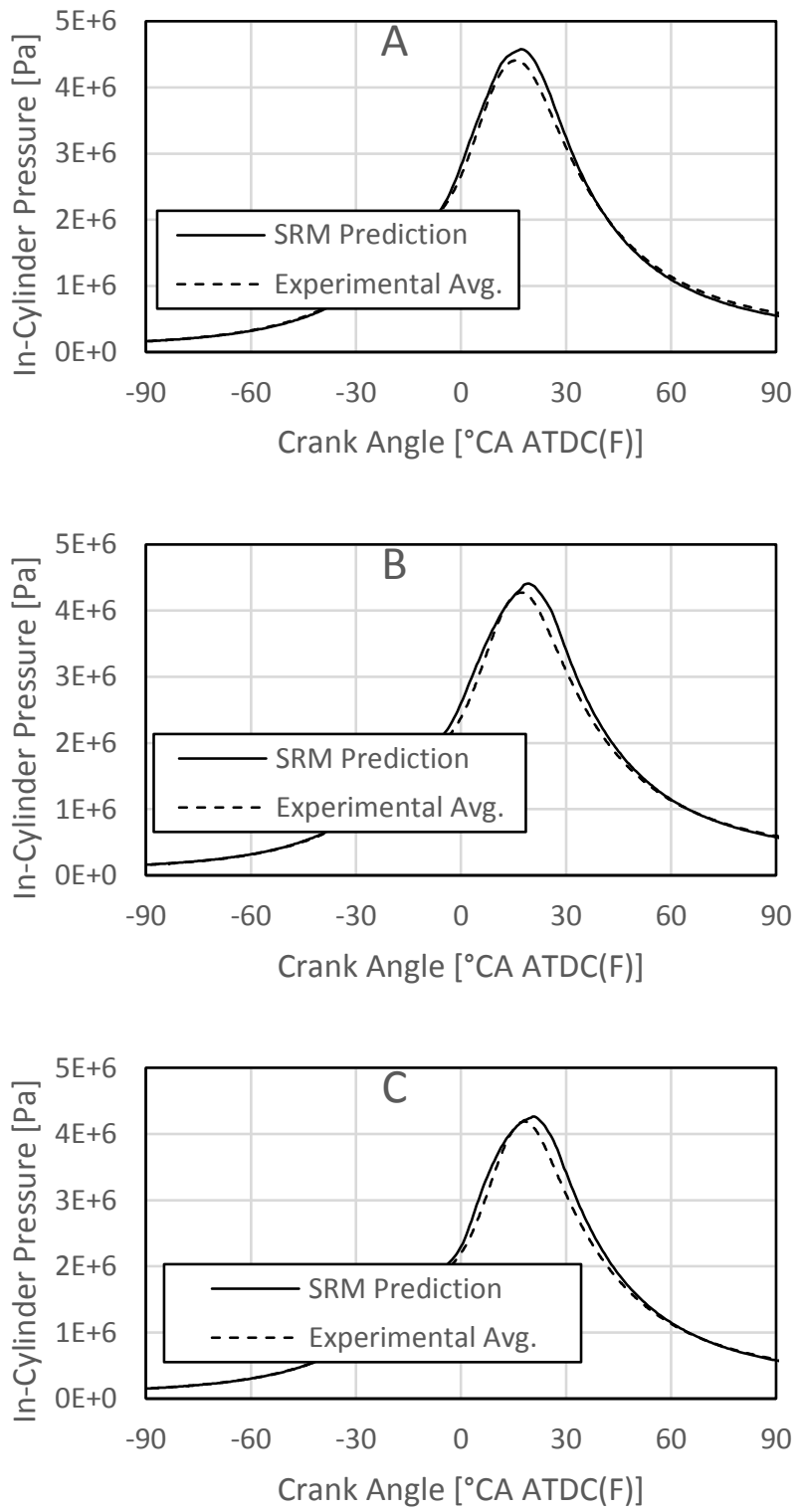

Figure 23: Predicted pressure and experimental pressure traces for key point 12 (graph A), key point 13 (graph B) and key point 14 (graph C) 2000rev/min VVT Combustion Prediction
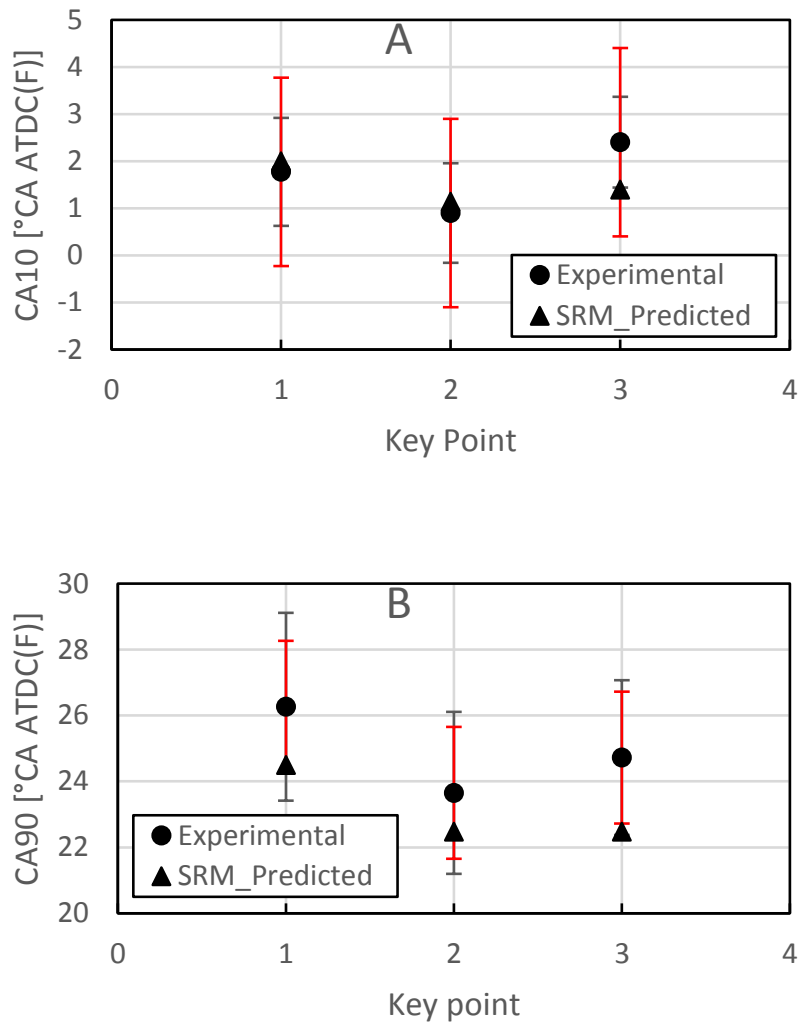

Figure 24: Predicted and Experimental CA10 (graph A) and CA90 (graph B) for different valve timings. Black error bands represent the experimental standard deviation. The $\pm 2{ }^{\circ} \mathrm{CA}$ confidence interval from experimental (averaged) values is shown by red error bands. 

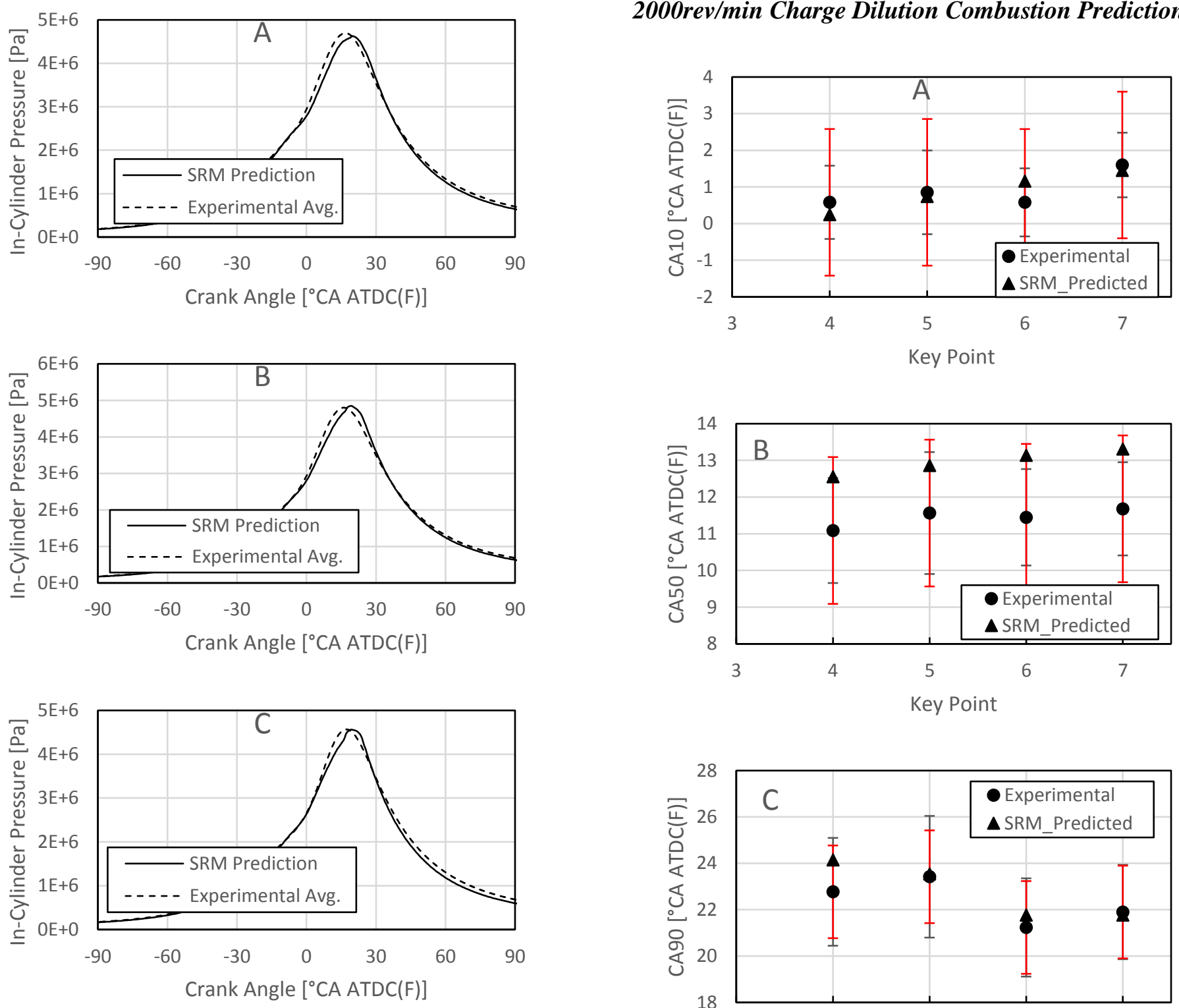

Figure 25: Predicted pressure and experimental pressure traces for key point 1 (graph A), key point 2 (graph B) and key point 3 (graph C)

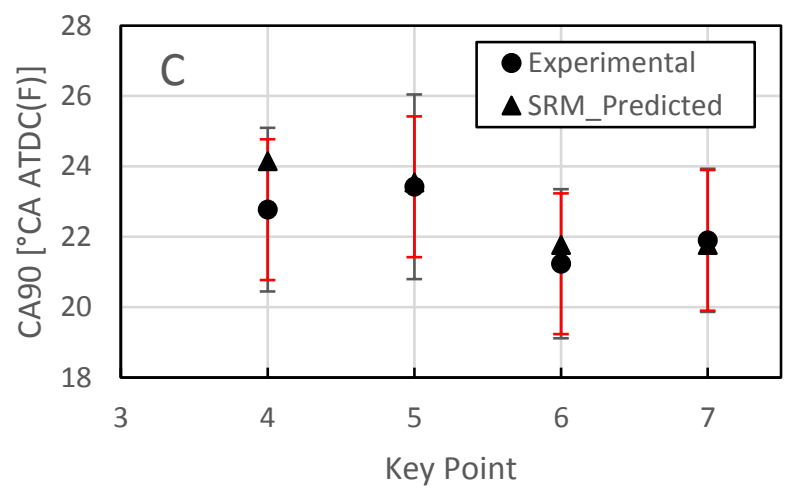

Figure 26: Predicted and Experimental CA10 (graph A) CA50 (graph B) and CA90 (graph C) for different charge dilution. Black error bands represent the experimental standard deviation. The $\pm 2{ }^{\circ} \mathrm{CA}$ confidence interval from experimental (averaged) values is shown by red error bands. 

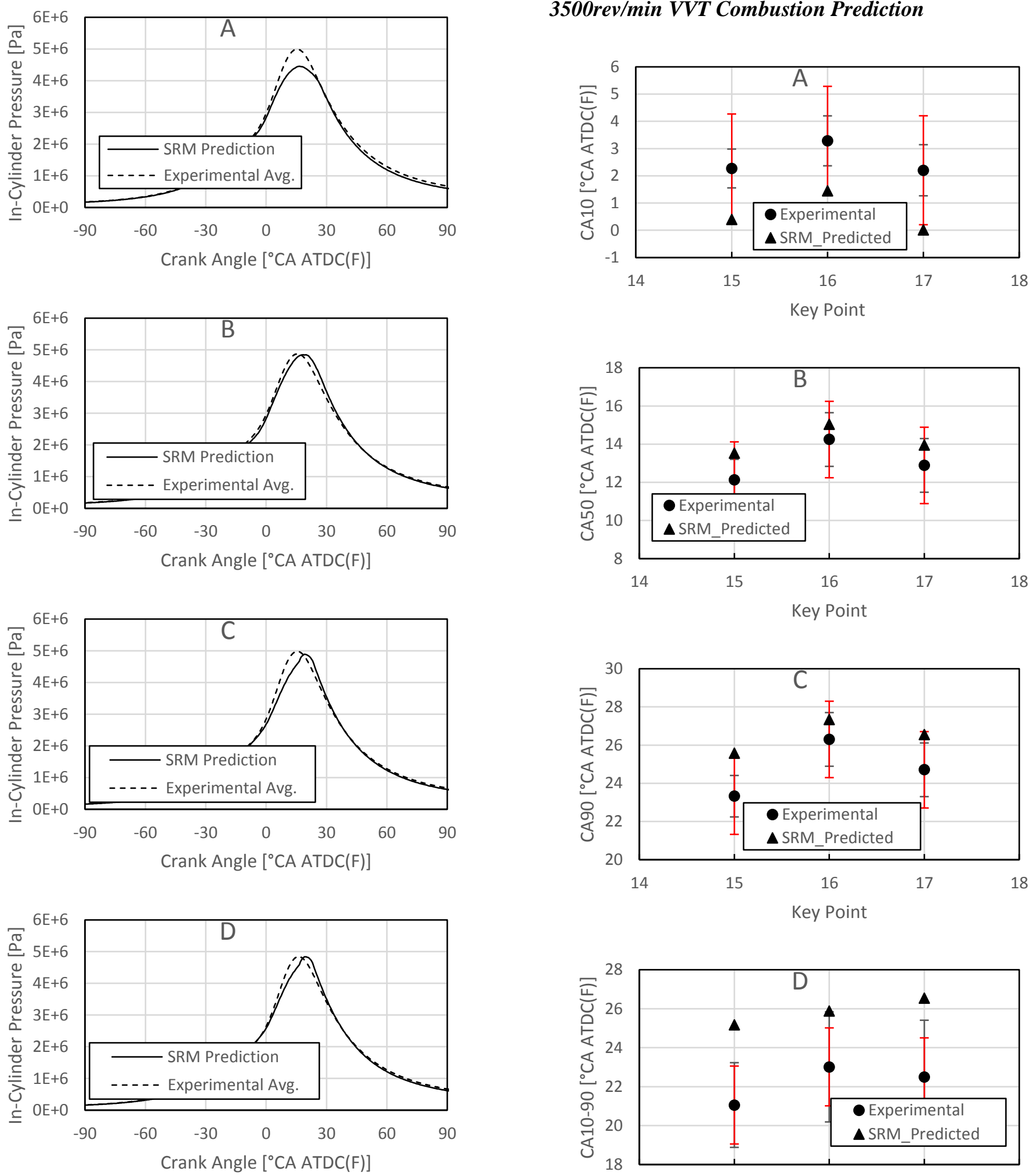

Figure 27: Predicted pressure and experimental pressure traces for key point 4

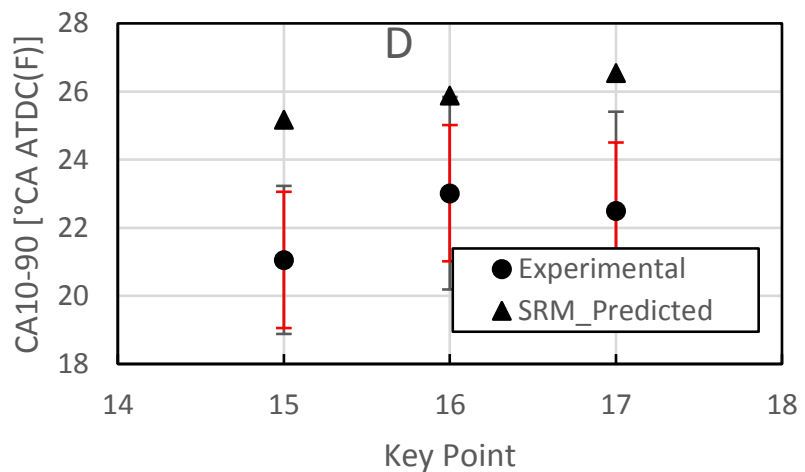

(graph A), key point 5 (graph B), key point 6 (graph C) and key point 7 (graph D)

Figure 28: Predicted and Experimental CA10 (graph A), CA50 (graph B) (graph C) and CA10-90 (graph D) for different valve timings. Black error bands represent the experimental standard deviation. The $\pm 2{ }^{\circ} \mathrm{CA}$ confidence interval from experimental (averaged) values is shown by red error bands. 


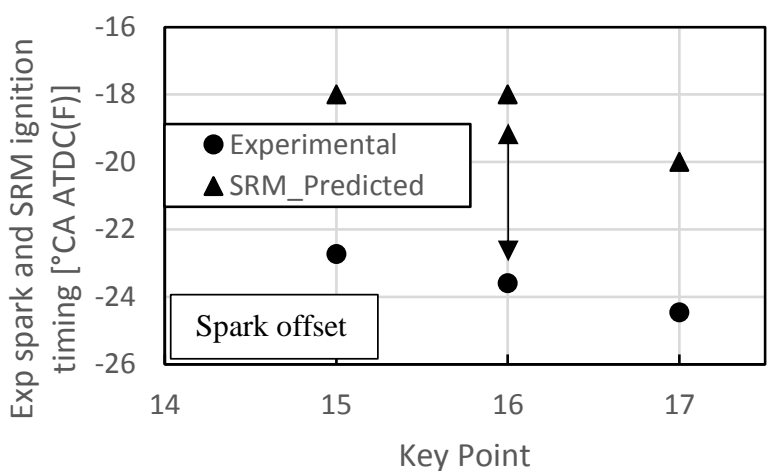

Figure 29: Experimental spark and SRM input timings comparison for different valve timings
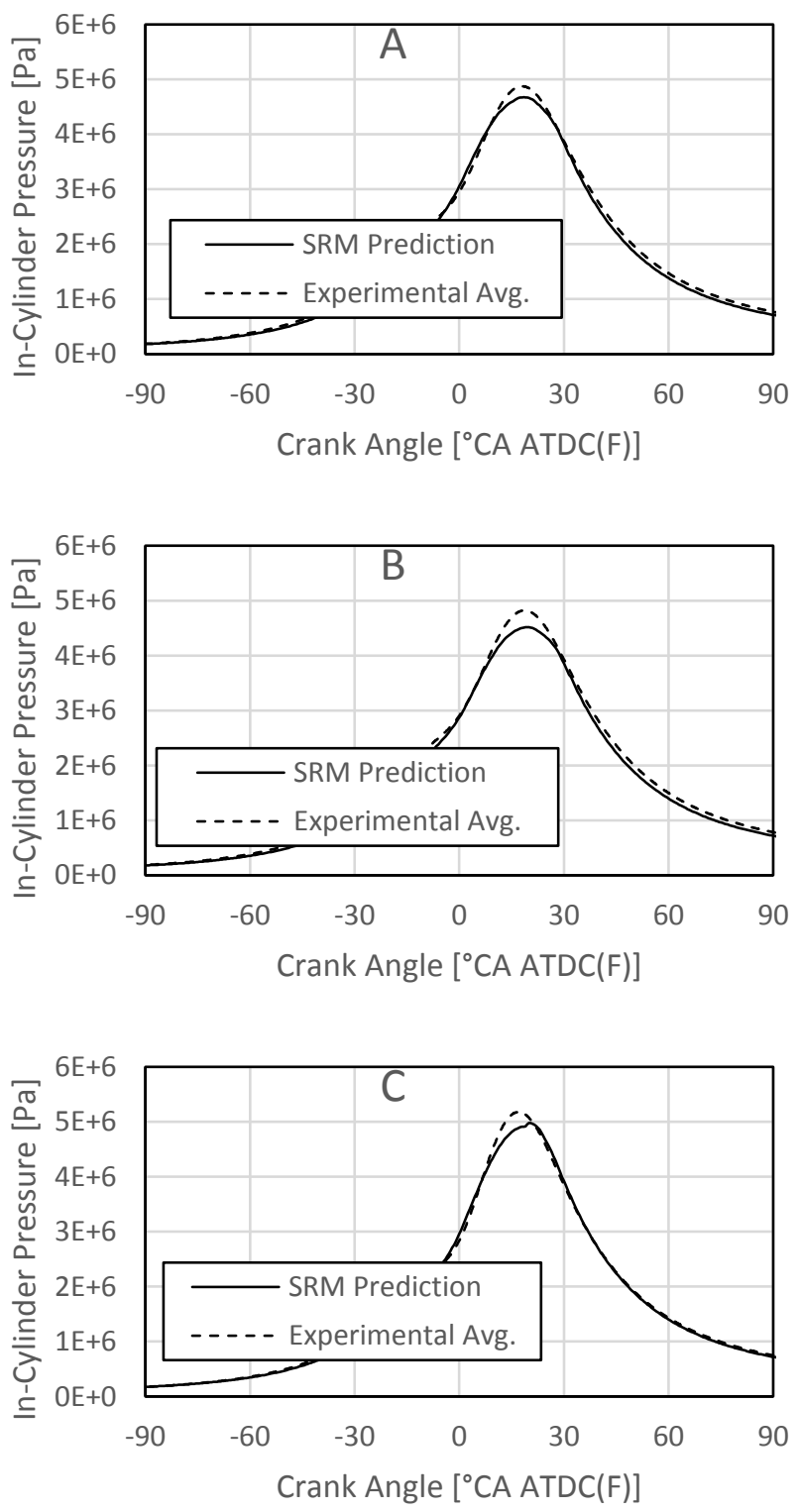

Figure 30: Predicted pressure and experimental pressure traces for key point 15 (graph A), key point 16 (graph B) and key point 17 (graph C)

18 of 20
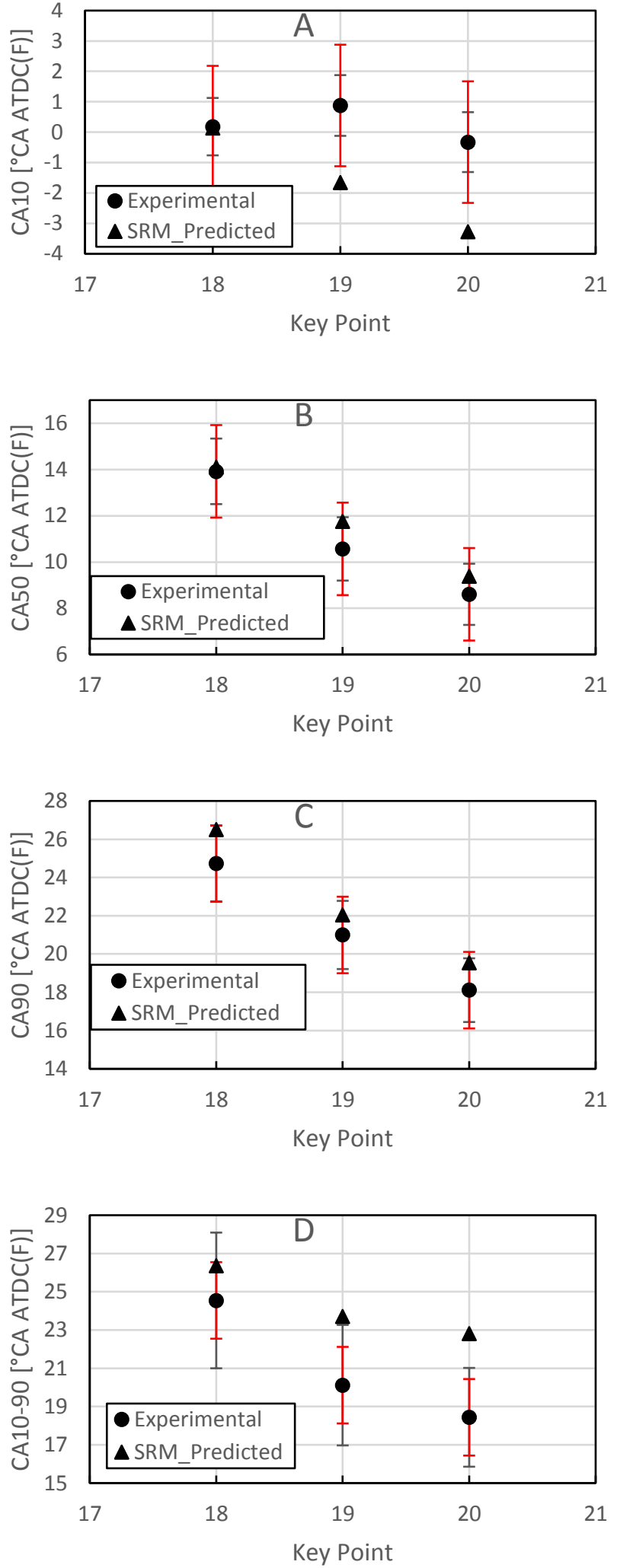

Figure 31: Predicted and Experimental CA10 (graph A), CA50 (graph B) (graph C) and CA10-90 (graph D) for different charge dilution. Black error bands represent the experimental standard deviation. The $\pm 2{ }^{\circ} \mathrm{CA}$ confidence interval from experimental (averaged) values is shown by red error bands. 


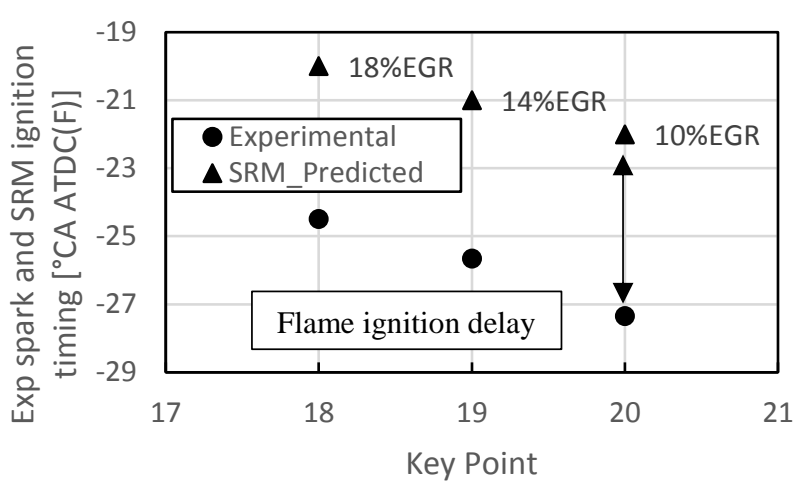

Figure 32: Experimental spark and SRM input timings comparison for different charge dilution
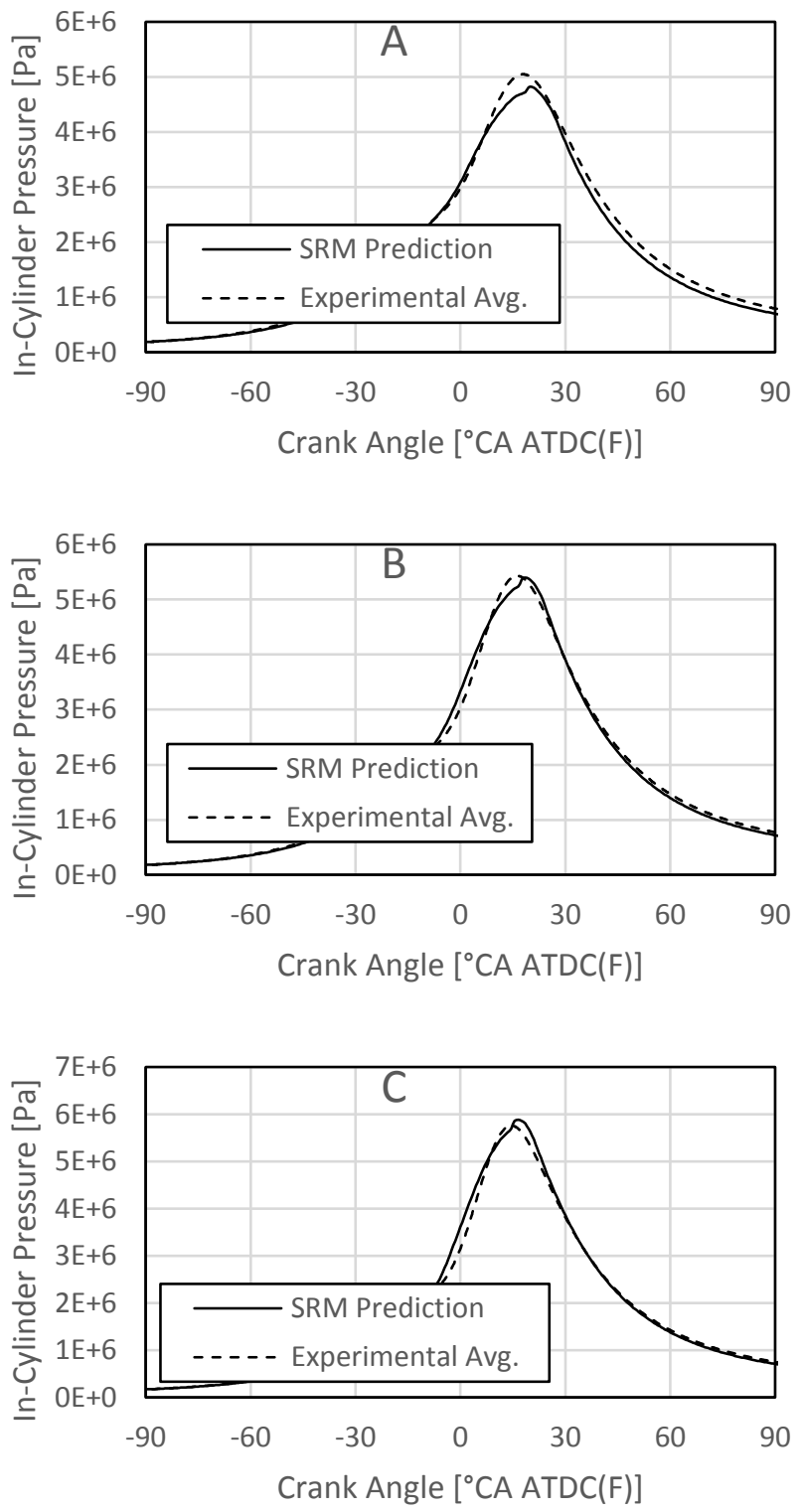

Figure 33: Predicted pressure and experimental pressure traces for key point 18 (graph A), key point 19 (graph B) and key point 20 (graph C) 5500rev/min VVT Combustion Prediction
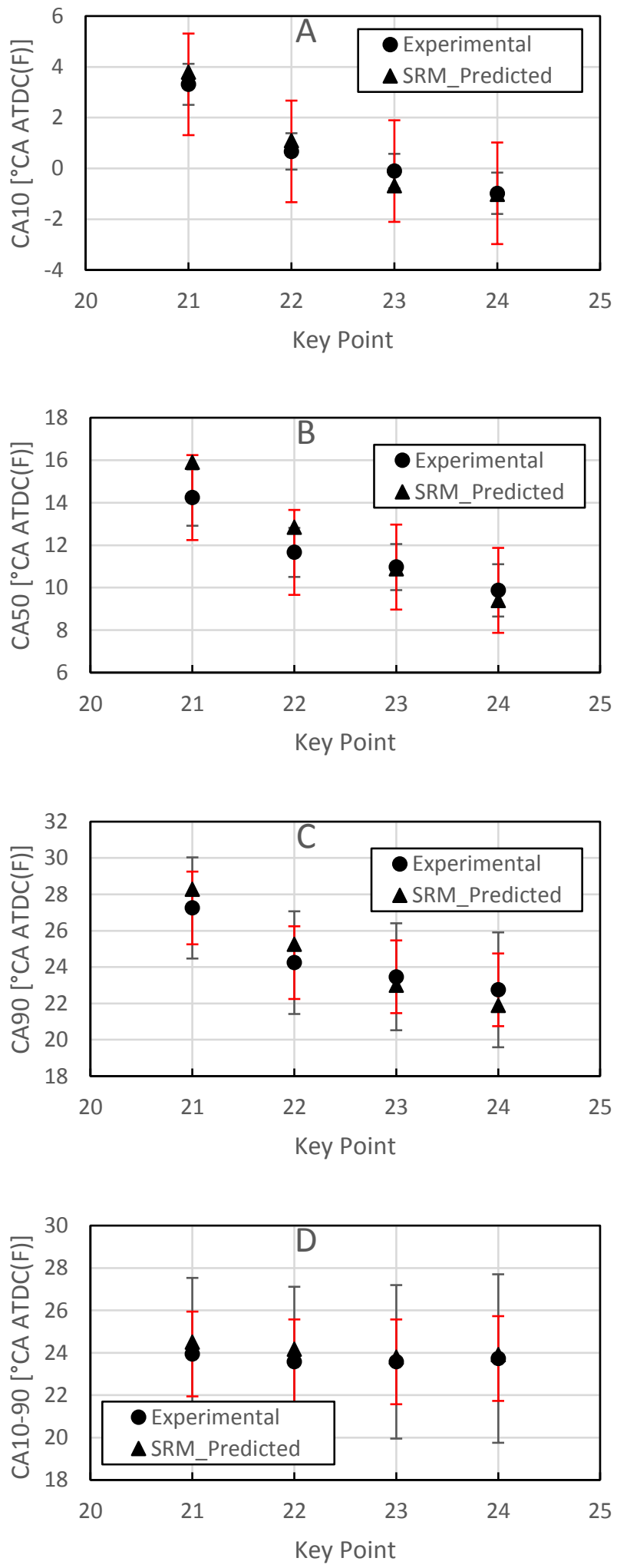

Figure 34: Predicted and Experimental CA10 (graph A), CA50 (graph B) (graph C) and CA10-90 (graph D) for different valve timings. Black error bands represent the experimental standard deviation. The $\pm 2{ }^{\circ} \mathrm{CA}$ confidence interval from experimental (averaged) values is shown by red error bands. 


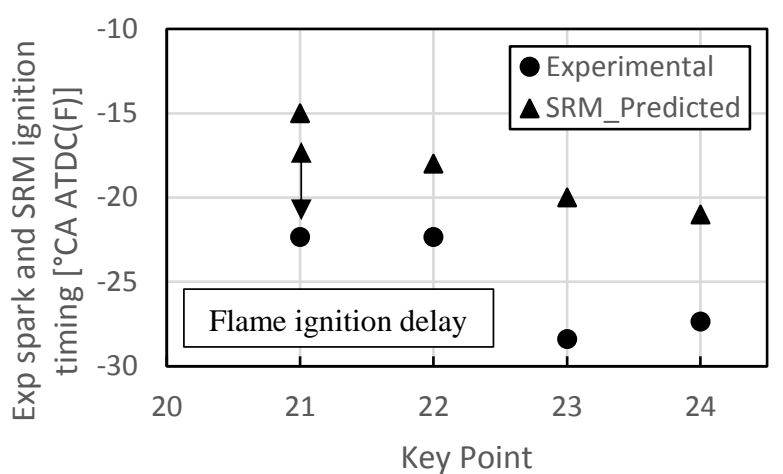

Figure 35: Experimental spark and SRM input timings comparison for different valve timings
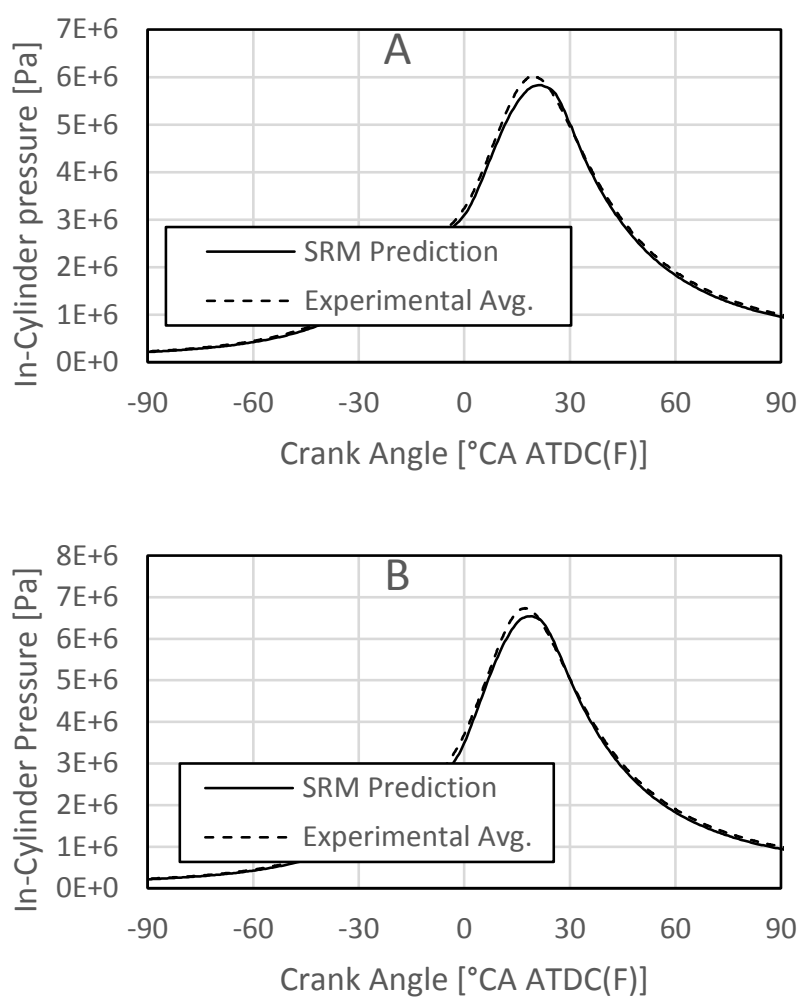
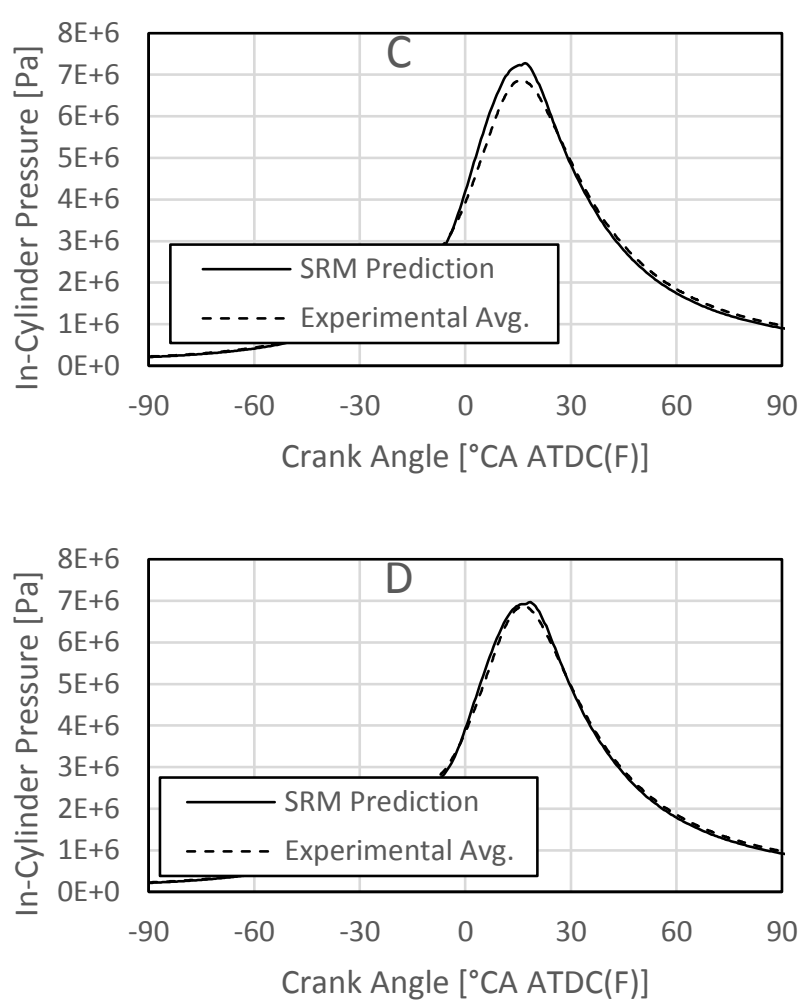

Figure 36: Predicted pressure and experimental pressure traces for key point 21 (graph A), key point 22 (graph B), key point 23 (graph C) and key point 24 (graph D) 